San Jose State University

SJSU ScholarWorks

Master's Theses

Master's Theses and Graduate Research

Fall 2013

\title{
Theoretical and Experimental Exploration of Gill Remodeling in Gambusia affinis
}

Barbara Tess Douglas

San Jose State University

Follow this and additional works at: https://scholarworks.sjsu.edu/etd_theses

\section{Recommended Citation}

Douglas, Barbara Tess, "Theoretical and Experimental Exploration of Gill Remodeling in Gambusia affinis" (2013). Master's Theses. 4385.

DOI: https://doi.org/10.31979/etd.7vyv-w6aq

https://scholarworks.sjsu.edu/etd_theses/4385

This Thesis is brought to you for free and open access by the Master's Theses and Graduate Research at SJSU ScholarWorks. It has been accepted for inclusion in Master's Theses by an authorized administrator of SJSU ScholarWorks. For more information, please contact scholarworks@sjsu.edu. 


\title{
THEORETICAL AND EXPERIMENTAL EXPLORATION OF GILL REMODELING IN GAMBUSIA AFFINIS
}

\author{
A Thesis \\ Presented to \\ The Faculty of Moss Landing Marine Laboratories \\ San José State University \\ In Partial Fulfillment \\ of the Requirements for the Degree \\ Master of Science
}

by

Barbara Tess Douglas

December 2013 
(C)2013

Barbara Tess Douglas

ALL RIGHTS RESERVED 
The Designated Thesis Committee Approves the Thesis Titled

THEORETICAL AND EXPERIMENTAL EXPLORATION OF

GILL REMODELING IN GAMBUSIA AFFINIS

by

Barbara Tess Douglas

APPROVED FOR MOSS LANDING MARINE LABORATORIES

SAN JOSÉ STATE UNIVERSITY

December 2013

Dr. Gregor Cailliet

Moss Landing Marine Laboratories

Dr. Lara Ferry

Mathematical \& Natural Sciences, Arizona State University

Dr. Kenneth Coale

Moss Landing Marine Laboratories

Dr. Erika McPhee-Shaw

Moss Landing Marine Laboratories 


\section{ABSTRACT \\ THEORETICAL AND EXPERIMENTAL EXPLORATION OF GILL REMODELING IN GAMBUSIA AFFINIS}

\section{By Barbara Tess Douglas}

In this thesis, the phenomenon of gill remodeling discovered in several species of fish is explored. Gill remodeling is achieved through an increase or decrease in cells within the interlamellar space, termed the interlamellar cell mass (ILCM). The effect of the ILCM on flow is explored using a theoretical model gill section. The model gill section was compared in three states: full ILCM, half ILCM, and clear (no ILCM). Differences in surface area, total flow, flow velocities, oxygen uptake, and available oxygen were compared between the three conditions. All parameters were distinctly larger for the model without the ILCM indicating that the ILCM is a significant barrier to flow and oxygen uptake.

The ability of mosquitofish, Gambusia affinis, to remodel its gills was explored experimentally through manipulation of temperature and salinity. Gambusia affinis were placed in aquaria that varied in temperature from $8^{\circ} \mathrm{C}$ to $26^{\circ} \mathrm{C}$ or in salinity from 0 psu to 20 psu. The ability of $G$. affinis to remodel its gills in response to temperature changes was confirmed. G. affinis had significantly larger respiratory surface area at the highest temperature due to a reduced ILCM and a significantly lower respiratory surface area at the lowest temperature due to an increase in the ILCM. Salinity was not shown to be a significant trigger of gill remodeling. 


\section{ACKNOWLEDGEMENTS}

Foremost, I want to express my sincere gratitude to my advisors Dr. Lara Ferry and Dr. Gregor Cailliet for their support of my Masters study and research and for never giving up on me. To Dr. Ferry I would like to say that I appreciate your substantial contributions of time, ideas, motivation, understanding, and funding. You helped me to have the courage to pursue an unusual and, to me, exciting thesis project. To Dr. Cailliet I would like to say thank you for sharing your time and your passion for Ichthyology. Thank you for your detailed notes and comments that helped me to refine my thesis.

I would like to thank the rest of my thesis committee: Dr. Kenneth Coale for his enthusiasm, insightful comments, and important final corrections and Dr. Erika McPheeShaw for giving me a start in my model analysis.

My sincere thanks also go to Dr. Michael Sneary for his immense generosity with his time in training me and in allowing me access to his lab and histology equipment. As well as to Larry Young for his considerable time helping to set up my lab space and advising on my IACUC proposal.

Thank you to Sara Tanner for your considerable time spent training and supporting me in the use of the scanning electron microscope.

Thank you to Dr. Lacey Gunter for kindly sharing your time and extensive knowledge of statistics and for being willing to help me work out the glitches.

Thank you to James Knuckey and Julie Khodayari for your hours in the lab and Darcy Douglas for help with data entry. I could not have finished without you. 
Finally, I would like to thank my family. To my parents, thank you for your endless love, for always supporting my ambitions, and for continually making me feel like "the greatest." To my second parents though marriage, thank you for your vast love and generosity. Thank you to my sweet children who make every day beautiful. Most of all, thank you to my loving, encouraging, and generally patient husband. Thank you for pushing me and supporting me in finishing this thesis. 


\section{TABLE OF CONTENTS}

FIGURES: PART 1 ............................................................. ix

FIGURES: PART 2 .............................................................. $x$

TABLES: PART 1 AND PART 2 ............................................. xii

Introduction................................................................... 1

PART 1: THEORETICAL ANALYSIS OF DIFFERENCES IN FLOW OVER FISH GILLS IN THREE MORPHOLOGICAL STATES ................. 4

Introduction........................................................... $\quad 5$

Methods............................................................... 12

Results.... ............................................................... 24

Surface Area....................................................... 24

Flows through gill model conditions............................ 25

Rate of oxygen diffusion........................................ 26

Oxygen uptake............................................... 27

Discussion.......................................................... 28

\section{PART 2: EXPERIMENTAL EXPLORATION OF GILL REMODELING OF} GAMBUSIA AFFINIS IN RESPONSE TO SALINITY AND TEMPERATURE CHANGES.......................................... 33

Introduction......................................................... 34

Methods................................................................ 38

Fish acquisition and holding................................... 38

Experimental procedure - temperature and salinity exposure .... 39

Experimental procedure - determining size effects............... 41 
Histological methods: preparation for light microscopy .......... 42

Histological methods: preparation for SEM .................... 43

Morphometry...................................................... 43

Data analysis ............................................... 45

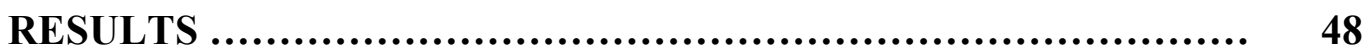

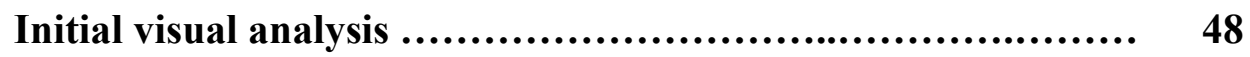

Size effects........................................................... 52

Temperature....................................................... 53

Salinity........................................................... 65

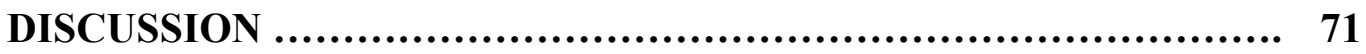

REFERENCES $\ldots . \ldots \ldots \ldots \ldots \ldots \ldots \ldots \ldots \ldots \ldots \ldots \ldots \ldots \ldots \ldots \ldots \ldots \ldots \ldots \ldots \ldots \ldots \ldots \ldots \ldots, \quad 77$ 


\section{FIGURES}

\section{PART 1: THEORETICAL ANALYSIS OF FLOW OVER FISH GILLS IN THREE MORPHOLOGICAL STATES}

Figure 1. Diagrams of a gill filament showing the lamellae and interlamellar cell mass. ..................................................... 6

Figure 2. Main features of general fish gill anatomy ....................... 8

Figure 3. Model gill section with the ILCM completely filling the interlamellar space............................................... 14

Figure 4. Model gill section with the ILCM half filling the inter-lamellar space................................................... 15

Figure 5. Model gill section with the ILCM absent from the inter-lamellar space

Figure 6. Diagram of the Hagen-Poiseuille theory of laminar flow between two parallel plates... 


\section{FIGURES}

\section{PART 2: EXPERIMENTAL EXPLORATION OF GILL REMODELING OF GAMBUSIA AFFINIS IN RESPONSE TO SALINITY AND TEMPERATURE CHANGES}

Figure 1. Diagram of a gill filament showing morphometric measurements taken.

Comparison of Q-Q plots and residuals verses predicted values for the

Figure 2. analysis of respiratory surface area with (A) and without (B)

outliers

Figure 3. General view of Gambusia affinis gill filaments viewed by light microscopy

Figure 4. General view of Gambusia affinis gill filaments viewed by scanning electron microscopy........................................

Figure 5. General view of Gambusia affinis gill filaments from a single individual in the $8^{\circ}$ Celcius temperature treatment

Figure 6. Mean respiratory surface area over time for each temperature treatment.

Figure 7. Mean protruding lamellar height (PLH) over time for each temperature

Figure 8. Mean protruding lamellar basal lengths over time for each temperature treatment.

Figure 9. Mean cross-sectional surface area (CSSA) between temperature treatments (A). Mean cross-sectional surface area (CSSA) over time (B).

Figure 10. Mean lamellar thickness (LT) between temperature treatments (A). Mean lamellar thickness (LT) over time (B)

Figure 11. Mean filament thicknesses over time for each temperature treatment... 64

Figure 12. Mean respiratory surface area over time (A). Mean respiratory surface area between salinity treatments $(\mathrm{B})$ 
Figure 13. Mean protruding lamellar height over time (A). Mean protruding lamellar height between salinity treatments (B) ...................... 66

Figure 14. Mean protruding lamellar basal length (PLBL) over time between salinity treatments.............................................. 68

Figure 15. Mean cross-sectional surface area (CSSA) over time (A). Mean crosssectional surface area (CSSA) between salinity treatments (B)......... 69

Figure 16. Mean lamellar thicknesses between salinity treatments............... 70

Figure 17. Mean filament thickness over time (A). Mean filament thickness between salinity treatments (B)................................ 71 


\section{TABLES}

\section{PART 1: THEORETICAL ANALYSIS OF FLOW OVER FISH GILLS IN THREE MORPHOLOGICAL STATES}

Table 1. Assumed dimensions of the model gill section...................... 17

Table 2. Reynolds numbers calculated for three flow velocities in freshwater at $20^{\circ}$ Celsius...................................................... 19

Table 3. Ratio of Bernoulli to Hagen-Poiseuille influences................. 22

Table 4. Results of Surface Area Calculations for Each Gill Model

Condition.

Calculated Values of Hagen-Poiseuille Flow and Velocity for Each

Table 5. Gill Model Condition....................................... 26

Calculated Rates of Oxygen Uptake Within Each Gill Model

Table $6 . \quad$ Condition

Oxygen diffusion rate and available oxygen within the model gill

Table 7 . section and for the total estimated respiratory surface....

\section{PART 2: EXPERIMENTAL EXPLORATION OF GILL REMODELING OF GAMBUSIA AFFINIS IN RESPONSE TO SALINITY AND TEMPERATURE CHANGES}

Table 1. Conditions within experimental aquaria

Table 2. Results of linear regression analysis for relationship between four different fish size measurements and respiratory surface area

Table 3. Significant simple main effects of time and temperature on respiratory surface area

Table 4. Significant simple main effects of time and temperature on protruding lamellar height 


\section{Introduction}

The purpose of this study was to explore the ability of some fishes to remodel their gill surface area. In 2003, researchers at the University of Oslo in Norway discovered that the crucian carp, (Carassius carassius) has the ability to change the surface area of its gills in response to hypoxia (Sollid et al., 2003). Hypoxic waters have oxygen concentrations below the critical oxygen concentration $\left(\left[\mathrm{O}_{2}\right]_{\text {crit }}\right)$ for the study species, or an oxygen concentration when they can no longer meet their energy requirements through aerobic metabolism alone. This was $9.4-23.5 \mu \mathrm{M}$ in previous studies (Matey et al., 2008; Sollid et al., 2003). When in normoxic waters (water having oxygen concentrations above the $\left[\mathrm{O}_{2}\right]_{\text {crit }}$,typically above $\left.62 \mu \mathrm{M}\right)$, the gills of $C$. carassius look club-like with much reduced surface area. When exposed to hypoxic waters, its gills look like typical fish gills with protruding lamellae and a much greater surface area. Remodeling is possible due to the presence of a mass of cells (termed the interlamellar cell mass, ILCM) between lamellae in normoxic waters. When exposed to hypoxic waters, a combination of increased cellular apoptosis (cell death) and reduced cell division diminishes the ILCM (Sollid et al., 2003).

The ability of fish to change the surface area of their gills is an interesting adaptation for dealing with opposing ionoregulatory (osmoregulatory) and respiratory needs. Fishes need oxygen to survive but must expend energy to maintain water and ion concentrations. The process of maintaining the balance of water and ion concentrations is termed either ionoregulation or osmoregulation. These terms are generally used interchangeably, the former often used when discussing freshwater fishes and the later 
when discussing marine fishes (Evans, Piermarini, \& Choe, 2005). A greater gill surface area (specifically the lamellar surface area) is beneficial for oxygen uptake but detrimental for maintenance of water and ion concentrations (Gonzalez \& McDonald, 1992). Having the ability to change lamellar surface area allows $C$. carassius to reduce metabolic costs associated with ion regulation when oxygen is readily available and enhance oxygen uptake when oxygen concentrations drop.

In subsequent years, researchers have found that three other species also have the ability to remodel their gills (Matey et al., 2008; Ong et al., 2007; Sollid et al., 2005). Two of these species are in the same order, Cypriniformes, as is C. carassius. However, one species is in the order Cyprinidontiformes, which is distantly related to the Cypriniformes. Another species, Salvelinus fontinalis (brook trout), when exposed to aluminum, exhibited a reaction which may be similar to the remodeling exhibited by $C$. carassius (McDonald et al., 1991). As this ability has been further explored, it seems it may not be as unique as was initially thought. Fishes in two distantly related orders seem to have exactly the same mechanism for dealing with the "Osmoregulatory Compromise." Based on this similarity in mechanism, the general hypothesis of this study was that this ability is much more widespread than is currently known. To test this hypothesis, a study species, Gambusia affinis, was chosen because it displays characteristics that may be indicative of an ability to remodel its respiratory surface area. This species was also chosen with the aim that this work will help to begin answering questions about the evolutionary history of gill remodeling.

Two general questions are explored in this thesis. First, how do the 
morphological changes in the gill affect flow and therefore oxygen diffusion over the fish gill? Second, can this change be induced in another related species?

\section{Specific research questions}

1. What can a theoretical model gill tell us about how flow is affected by changes in the interlamellar cell mass? This is explored in part 1.

2. Part 2: Can gill remodeling be induced in G. affinis, by changes in temperature? This is explored in part 2.

3. Part 2: Can gill remodeling be induced in G. affinis by changes in salinity? This is explored in part 2. 
PART 1: THEORETICAL ANALYSIS OF FLOW OVER FISH GILLS IN THREE MORPHOLOGICAL STATES 


\section{Introduction}

In this study, differences in flow over a model fish gill in three different conditions were examined. These conditions relate to experimental work (Part 2 of this thesis) in which a surprising physiological/ morphological adaptation to hypoxia was discovered. In 2003, researchers at the University of Oslo in Norway, discovered that the crucian carp, Carassius carassius, has the ability to change the surface area of its gills in response to hypoxia, termed 'gill remodeling' (Sollid et al., 2003). This change in surface area is achieved with a build-up of cells called the interlamellar cell mass (ILCM). A generalized diagram of a gill filament with the ILCM under normoxic (A) and hypoxic (B) conditions is shown in Figure1. Normoxic water is water having oxygen concentrations above the critical oxygen concentration, $\left[\mathrm{O}_{2}\right]_{\text {crit }}$, or the oxygen concentration when they can no longer meet their energy requirements through aerobic metabolism alone. Hypoxic water is water having oxygen concentrations below the $\left[\mathrm{O}_{2}\right]_{\text {crit. }}$ When in normoxic waters, the gills of the C. carassius look club-like with a much reduced surface area. When exposed to hypoxic waters, the gills of C. carassius look like typical fish gills with protruding lamellae and a much larger surface area (Sollid et al., 2003).

The change in surface area under hypoxic conditions has important physiological consequences (changes in chloride fluxes, effects on aerobic swimming capacity, effects on ammonia excretion etc.) that have been explored in several studies (Mitrovic \& Perry, 2009; Dejana Mitrovic, Dymowska, Nilsson, \& Perry, 2009; Perry et al., 2012; Perry, Schwaiger, Kumai, Tzaneva, \& Braun, 2010; Sandvik, Nilsson, \& Jensen, 2012; Sollid et 
al., 2005; Sollid et al., 2006). The morphological change achieved in gill remodeling may also have gross-level physical consequences. As can be seen in Figure 1, the shape of the gill tissues changes with the build-up and degradation of the ILCM. This change in shape may affect flow of ambient water through the gill tissues. Changes in flow through gill tissues, specifically past lamellae, may have important consequences for oxygen uptake. Using a model fish gill section, the expected effects of the ILCM on flow and oxygen uptake were explored in this study.

A

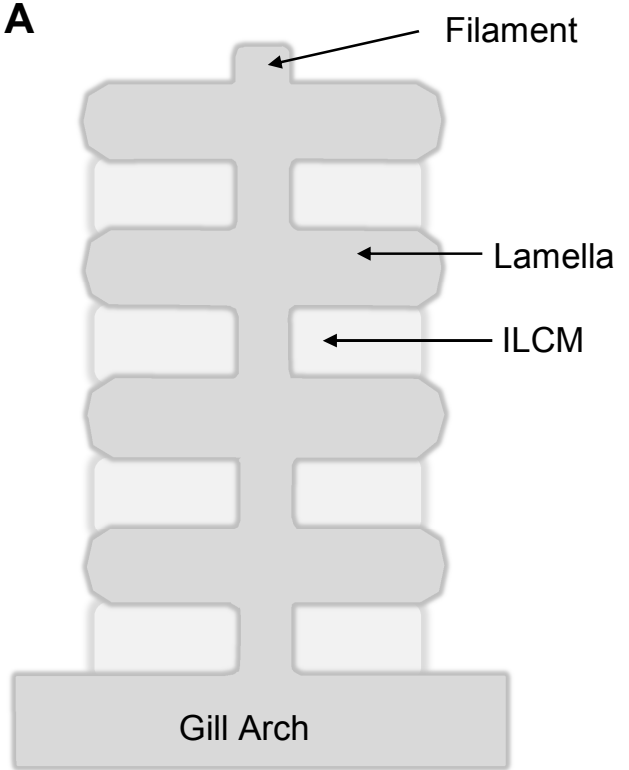

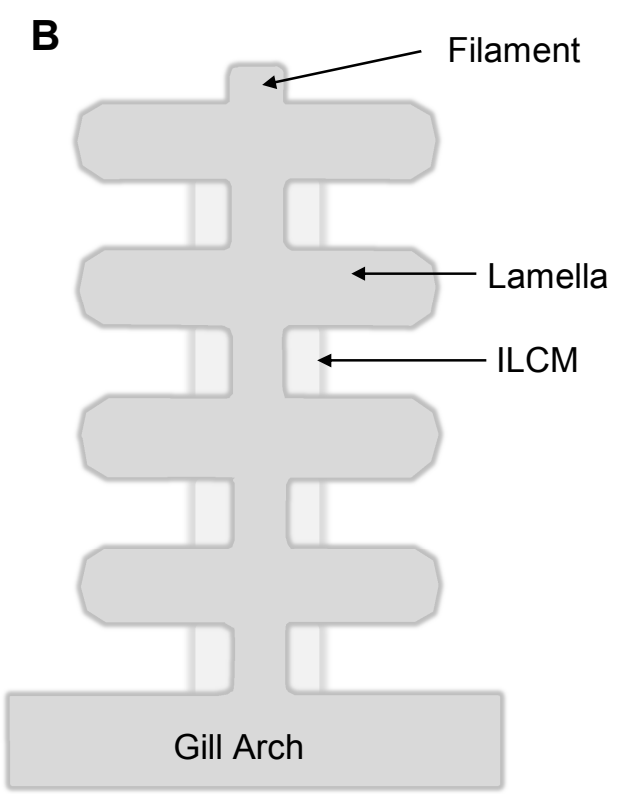

Figure 1. Diagrams of a gill filament showing the lamellae and interlamellar cell mass. (A) shows the gill filament under normoxic conditions. (B) shows the gill filament under hypoxic conditions.

Teleost (more derived bony) fishes have two sets of four bony gill arches which are located just behind the head region on both sides of the fish. The ends of each gill arch attach to structures in the roof and the floor of the buccal cavity. Each gill arch 
supports two rows of filaments. Each filament serves to supply blood to small projections on its surface called lamellae. The lamellae are the primary site of oxygen exchange with the surrounding water (Evans et al., 2005; Graham, 2006; Wilson \& Laurent, 2002). A single row of filaments is called a hemibranch. The two rows of filaments on one bony arch, together, comprise a holobranch. The four holobranchs line up to create five branchial slits through which water flows. The hemibranchs line up with the tips of one hemibranch touching the tip of a hemibranch from the adjacent holobranch or touching the walls of the buccal chamber (Figure 2). This creates a seal that helps create a pressure gradient that pushes water over the gills and directs flow between the lamellae rather than over the tops of them. 

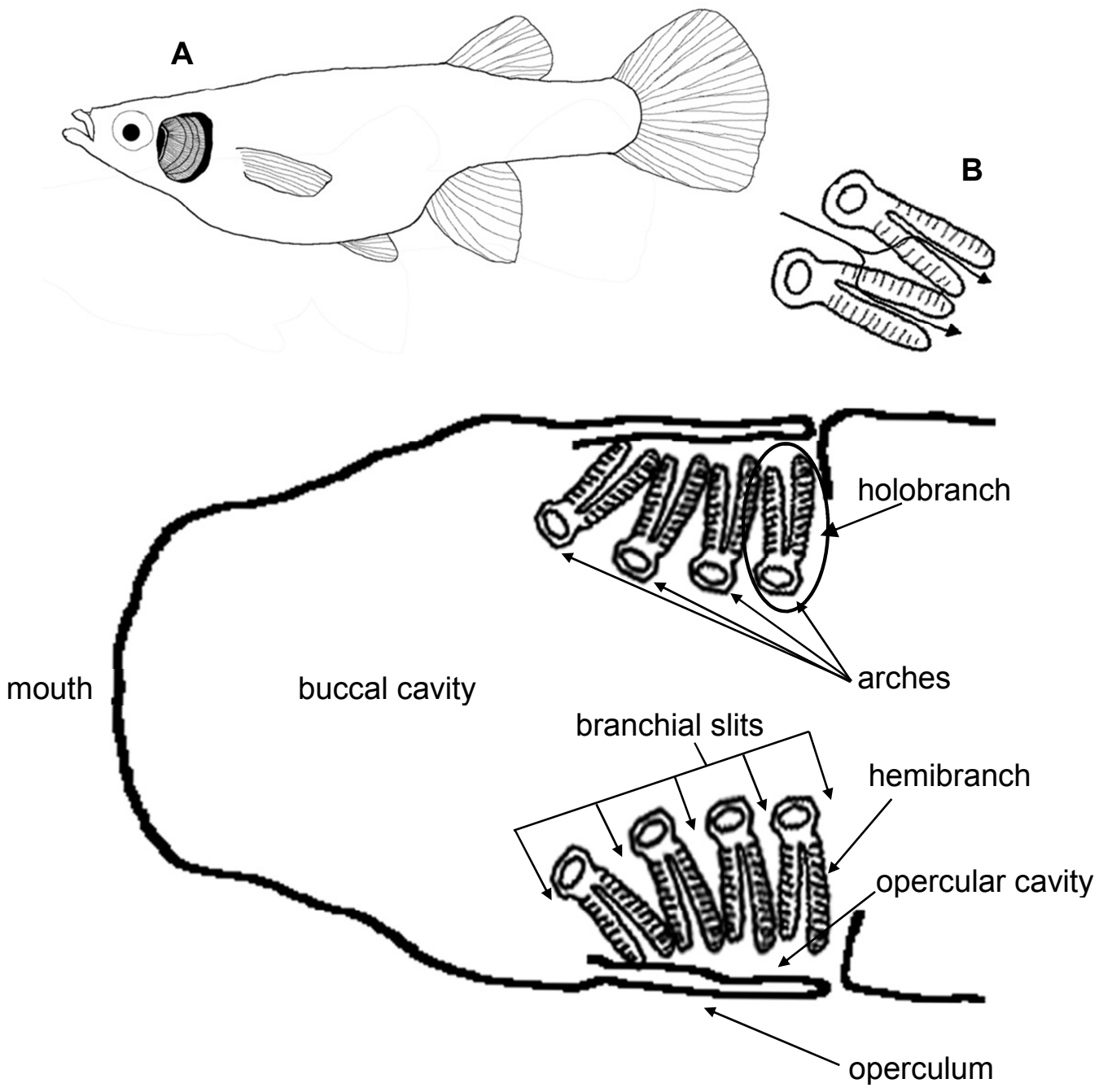

Figure 2. Main features of normal fish gill anatomy. (A) Location of the four gill arches within a fish. (B) Flow of water between holobranchs, through the spaces between lamellae, and out the middle of each holobranch.

Fishes must keep fresh, oxygenated water flowing over the gills to breathe. There are two different respiratory strategies fishes use to do this: ram ventilation and buccal pumping (Helfman, Collette, Facey, \& Bowen, 2009). In ram ventilation, a fish uses its swimming muscles to generate flow. If the fish swims at a relatively high speed, it can 
push water over its gills by simply keeping its mouth slightly open as it swims. Some active pelagic species, such as large tunas, are obligate ram ventilators. They must swim constantly to breathe.

The second, and more widespread, strategy for generating flow is buccal pumping. Fishes achieve buccal pumping by contraction of muscles controlling the floor of the buccal cavity. As the fish opens the mouth, the floor of the buccal cavity is depressed to create negative pressure that sucks water into the buccal cavity. The mouth closes, and the floor of the buccal cavity is pushed upward which creates positive pressure and pushes water over the gills into the opercular cavity. At the same time the opercular valve is opened allowing water to flow out (Helfman et al., 2009).

This unidirectional flow of water over the gills is important in the efficient uptake of oxygen. It is especially important because breathing in water is much more difficult than breathing in air. The concentration of oxygen in air at sea level is approximately $8,930 \mu \mathrm{M}$. The concentration of oxygen in freshwater is $258 \mu \mathrm{M}$ (at $25^{\circ} \mathrm{C}, 1 \mathrm{~atm}$ ) and in seawater is $211 \mu \mathrm{M}\left(25^{\circ} \mathrm{C}, 35 \mathrm{PSU}, 1 \mathrm{~atm}\right)$ (Olsen, Farrell, \& Lutz, 2006). The concentration of oxygen in water is only between $2-4 \%$ of the concentration in air. Breathing in water is also more difficult because water is 840 times more dense and 60 times more viscous than air (Graham, 2006). A fish (or any other water breathing organism) has to expend more energy than a terrestrial organism to push a thicker medium with less available oxygen over its respiratory surface.

Another feature of fish gills that helps in the efficient uptake of oxygen is the counter current flow of blood in the lamellae. The gills are supplied with blood via the 
afferent branchial artery with low oxygenated blood coming from the body tissues. This artery runs along the length of each gill arch supplying blood to the afferent filamental artery. The afferent filamental artery runs the length of each filament and supplies blood to each lamella. The lamellae are formed by a one cell thick epithelium supported by pillar cells interspersed between the epithelial cells. Blood flows across the lamellae in a sheet through the spaces around the pillar cells. The direction of blood flow is opposite of the direction of flow of water between the lamellae. This counter current flow means that the blood containing the lowest concentration of oxygen meets the water containing the lowest concentration of oxygen . Likewise, the blood containing the highest concentration of oxygen meets the water containing the highest concentration of oxygen. This maintains a constant concentration gradient of oxygen that pulls oxygen into the blood.

The gills are an important multifunctional organ system. As described above, the lamellae are the main site of oxygen uptake for most fishes. However, they are also the site of ion exchange, water flux, $\mathrm{pH}$ regulation, and nitrogenous waste excretion (Evans et al., 2005; Graham, 2006; Wilson \& Laurent, 2002). The structure of the gills must support all of these functions. However, the different functions do not all benefit from the same conditions. Lamellar surface area is the most important example of this. Increased lamellar surface area aids oxygen uptake but may exacerbate ion and water balance. The process of maintaining ion and water concentrations is termed either ionoregulation or osmoregulation (used interchangeably), the former typically used when discussing freshwater fishes and the later when discussing marine fishes (Evans et al., 
2005). A fish's lamellar surface area is likely to be a compromise between increasing oxygen uptake and minimizing ion and water loss across the gills. This is called the “Osmoregulatory Compromise" (Gonzalez \& McDonald, 1992). Individual fishes have several mechanisms for dealing with the competing respiratory and ionoregulatory (osmoregulatory) needs. The mechanism dealt with in this study is the ability to remodel gills to alter respiratory surface area in response to changing environmental conditions. This ability was first discovered in the crucian carp, C. carassius (Sollid et al., 2003). Researchers have found that remodeling of gill respiratory surface area can be induced by exposure to hypoxic waters in C. carassius, Carassius auratus (goldfish), and in Gymnocypris prezewalskii (Lake Qinghai scaleless carp) (Matey et al., 2008; Sollid et al., 2005, 2003). Temperature changes, that increase metabolism and therefore oxygen demands, were also shown to induce a change in C. carassius and C. auratus (Sollid, Weber, \& Nilsson, 2005). Another study (Ong et al., 2007), found that the amphibious Kryptolebias marmoratus (mangrove killifish) is also able to reversibly remodel lamellar surface area in response to aerial exposure. This change in morphology is made possible by the presence of a mass of cells (termed the interlamellar cell mass, ILCM) in between their lamellae in normoxic waters. When the fish are exposed to hypoxic waters the fish begin to degrade and slough off the ILCM to reveal more surface area.

As discussed above, a change in respiratory surface area because of the loss or gain of the ILCM has important consequences for oxygen uptake and ion flux. The change in morphology caused by the loss and gain of the ILCM also has important consequences. The change in the ILCM changes the shape of the filament and redirects 
water flow though the gills. As described above, in most fishes water flows in between the lamellae. However, when the ILCM is present, water flow is redirected over the tops of the lamellae. This change in flow could have important effects on the uptake of oxygen. Understanding these effects is important in understanding the ability of these (and possibly other) fishes to remodel their gills. If flow conditions enhance oxygen uptake when oxygen uptake is most important (during hypoxia, with a diminished or absent ILCM), it would further support the efficacy of gill remodeling. If flow conditions during hypoxia diminish the ability to uptake oxygen, one might ask: how adverse are these flow effects and are they small in comparison to the advantage of increased surface area? In addition, the change in flow with the presence of the ILCM could enhance oxygen uptake. This could counter the loss in oxygen uptake because of the decreased surface area. In this study a simple model gill section is described and used to compare the flow of water over the gills in the presence and absence of the ILCM.

\section{Method}

To understand how the presence of the ILCM affects flow across a fish gill, a model gill section of three filaments in close proximity was created. Figures 3,4 , and 5 show the same model gill section with lamellae covered by the ILCM (full), with the lamellae half covered by the ILCM (half), and with the lamellae fully exposed (clear), respectively. It is assumed within this model that the filament surface is non-respiratory and is not included in surface area estimates. Various dimensions within the model gill were assigned values based on measurements taken from the gills of Gambusia affinis 
(mosquitofish) and dependent on the model gill condition (Figures 3, 4, and 5). Table 1 lists the dimensions, their labels, and their assigned values. Several environmental and gill characteristics were assumed to be constant to focus on the main effect of the ILCM, including: water pressure across the model gill section, lamellar and filament thicknesses, blood perfusion, and gill microstructures. These three model conditions were used as the basis of several calculations described below. 


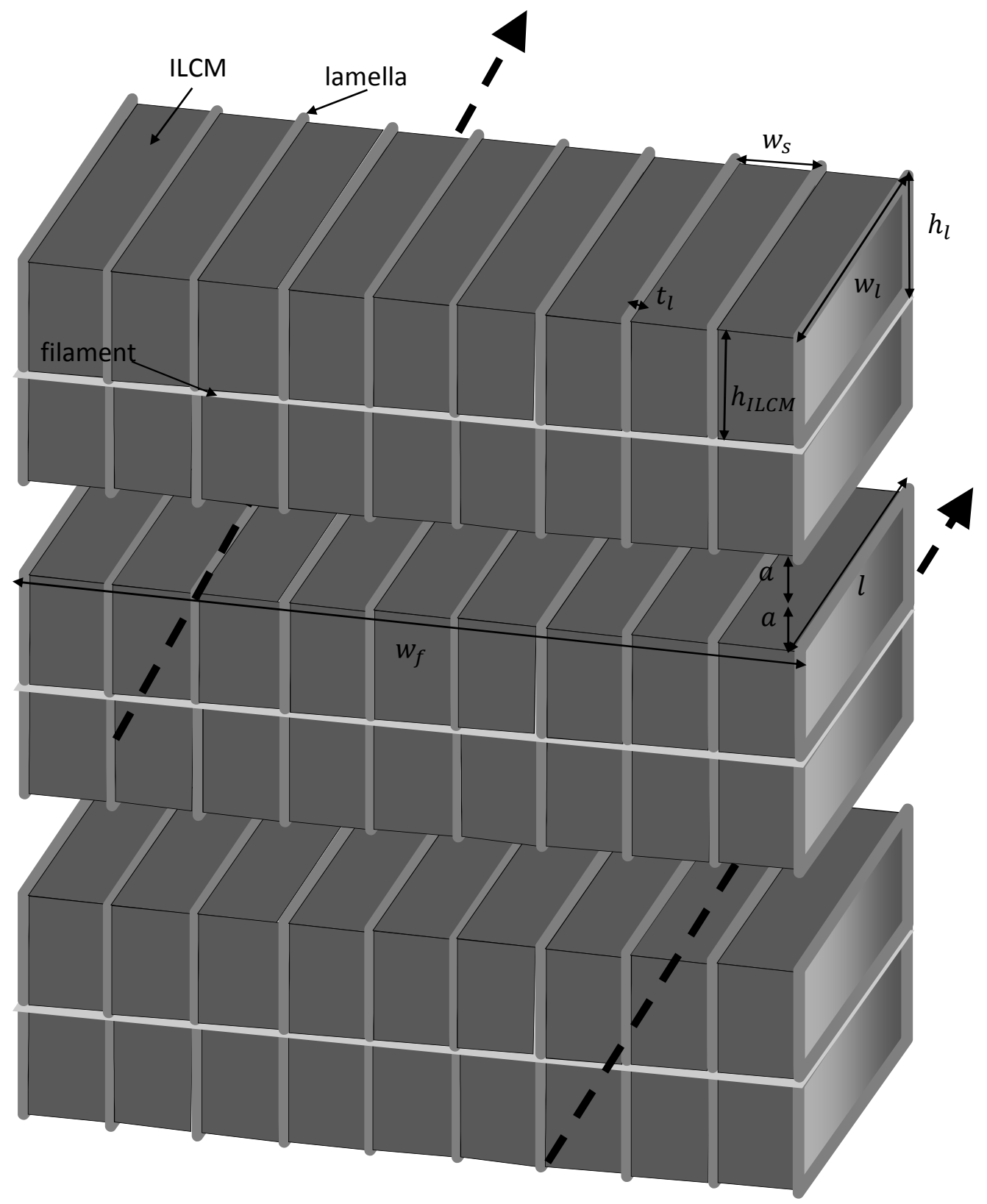

Figure 3. Model gill section with the ILCM completely filling the inter-lamellar space. Labeled dimensions on the top filament relate to surface area calculations. Labeled dimensions on the middle filament relate to Hagen-Poiseuille flow dimensions shown in Figure 6. Dashed arrows represent the direction of water flow through the gill section. 


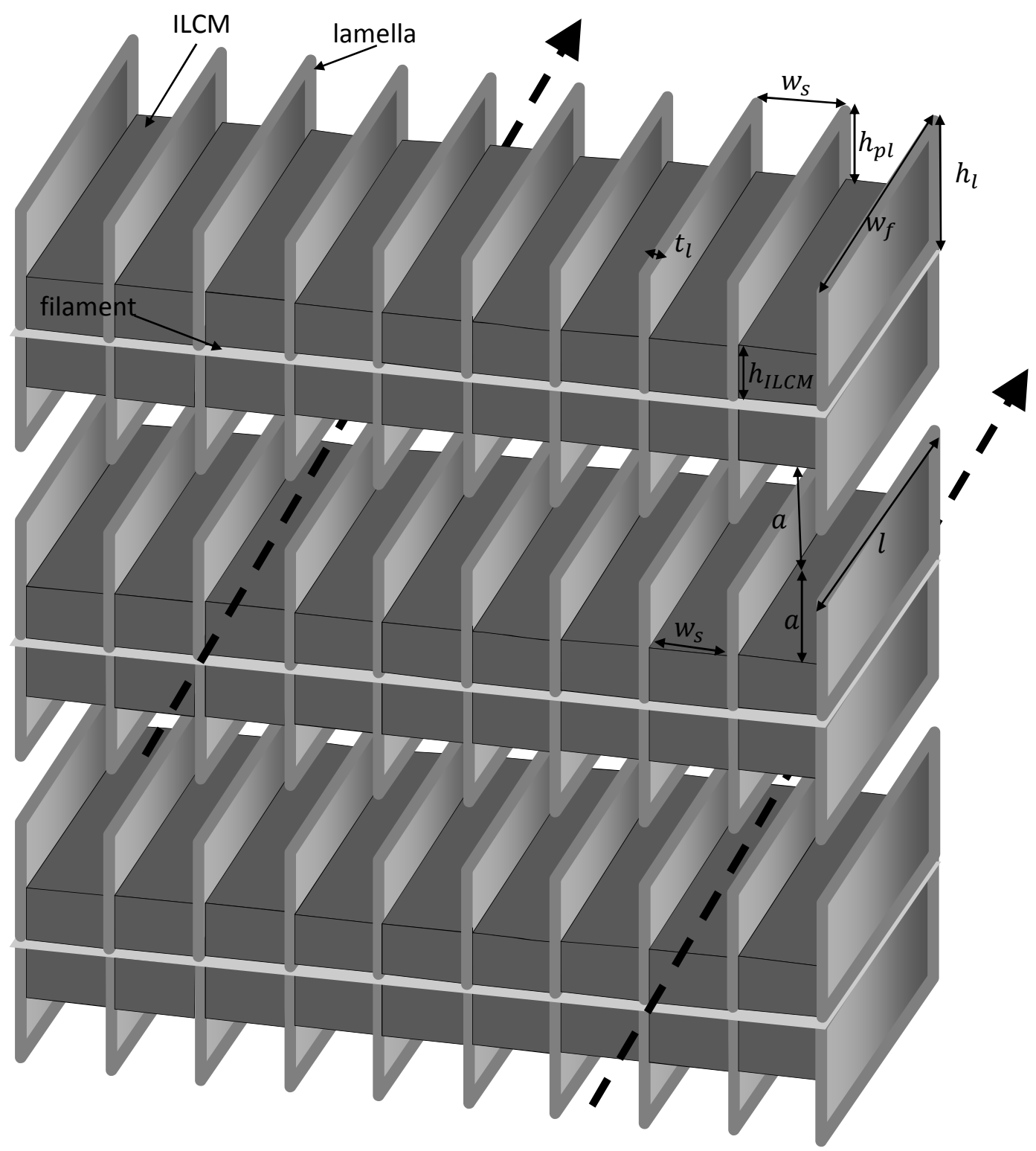

Figure 4. Model gill section with the ILCM half filling the inter-lamellar space. Labeled dimensions on the top filament relate to surface area calculations. Labeled dimensions on the middle filament relate to Hagen-Poiseuille flow dimensions shown in Figure 6. Dashed arrows represent the direction of water flow through the gill section. 


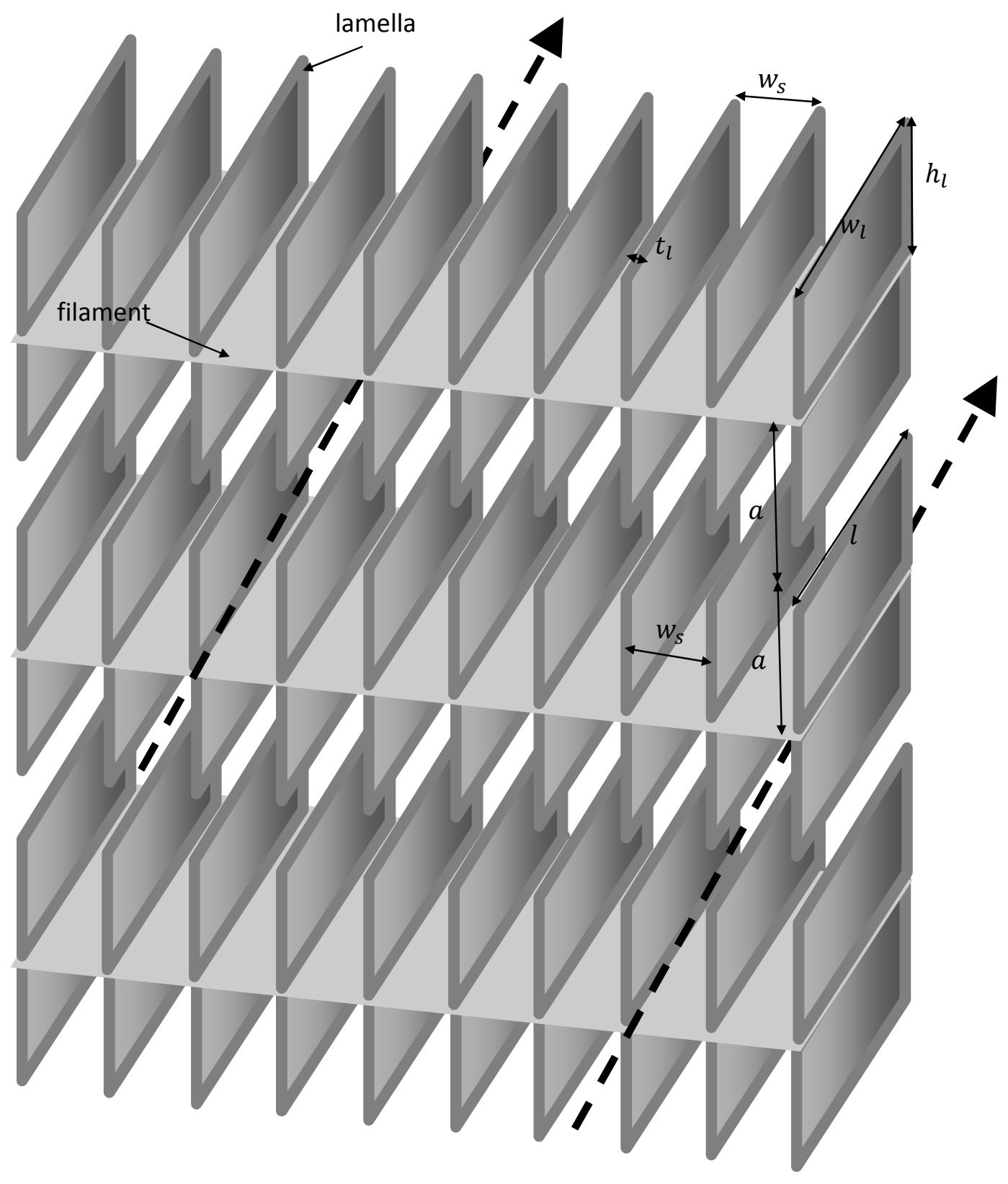

Figure 5. Model gill section with the ILCM absent from the inter-lamellar space. Labeled dimensions on the top filament relate to surface area calculations. Labeled dimensions on the middle filament relate to Hagen-Poiseuille flow dimensions shown in Figure 6. Dashed arrows represent the direction of water flow through the gill section. 
Table 1.

Assumed dimensions of the model gill section.

\begin{tabular}{|c|c|c|}
\hline Dimension & Label & Value \\
\hline Width of the lamellae & $w_{l}$ & $150 \mu \mathrm{m}$ \\
\hline Height of lamellae & $h_{l}$ & $80 \mu \mathrm{m}$ \\
\hline Height of the ILCM & $h_{I L C M}$ & $\begin{array}{c}\text { Full: } 80 \mu \mathrm{m} \\
\text { Half: } 40 \mu \mathrm{m}\end{array}$ \\
\hline $\begin{array}{c}\text { Width of the space between } \\
\text { lamellae }\end{array}$ & $w_{s}$ & $20 \mu \mathrm{m}$ \\
\hline $\begin{array}{c}\text { Height of the protruding } \\
\text { part of the lamella }\end{array}$ & $h_{p l}$ & $40 \mu \mathrm{m}$ \\
\hline $\begin{array}{c}\text { Thickness of the lamella } \\
\text { Width of the filament } \\
\text { section }\end{array}$ & $t_{l}$ & $6 \mu \mathrm{m}$ \\
\hline $\begin{array}{c}\text { Half the distance between } \\
\text { the parallel surfaces }\end{array}$ & $w_{f}$ & $240 \mu \mathrm{m}$ \\
\hline $\begin{array}{c}\text { Number of lamellae in the } \\
\text { model }\end{array}$ & $N_{l}$ & $\begin{array}{c}\text { Hall: } 5 \mu \mathrm{m} \\
\text { Clear: } 45 \mu \mathrm{m}\end{array}$ \\
\hline $\begin{array}{c}\text { Number of spaces in } \\
\text { between lamellae (equal to } \\
\left.N_{l}-1\right)\end{array}$ & $N_{s}$ & 10 \\
\hline $\begin{array}{c}\text { Number of surfaces } \\
\text { exposed to ambient water }\end{array}$ & $N_{e s}$ & 6 \\
\hline
\end{tabular}

Note: Values for each dimension were taken from averages measured on the gills of G. affinis.

To determine the overall magnitude of the change in the surface area between the three conditions, total surface area was calculated for each gill model condition. The edges of the model (front, back, and ends) were not included in surface area estimates. Only surfaces that correspond with a pipe-flow model were considered in this model (Vogel, 2003). These surfaces were those between adjacent filaments, through which water flows, indicated by dashed lines in Figures 3-5. Thus, the surface area included the ends of the lamellae and the surface of the ILCM facing the adjacent filament in the full model condition and this plus the sides of the lamellae exposed by the reduced ILCM in 
the half model condition. In the clear model condition, the surface area included the ends of the lamellae and sides exposed by the absence of the ILCM. The equations below are divided into respiratory and limited-respiratory surface areas. Respiratory surface area is the surface area of the lamellae in direct contact with ambient water. Limited-respiratory surface area is the surface area of the ILCM in contact with ambient water. Total surface area is the sum of the respiratory and limited respiratory surface areas. Because the ILCM is not present in the clear model, the respiratory surface area is equal to the total surface area.

\section{Full:}

Respiratory $S A=N_{e s}\left(N_{l}\left(t_{l} * w_{l}\right)\right)$

Limited $S A=N_{e s}\left(N_{S}\left(w_{s} * w_{l}\right)\right)$

\section{Half:}

$$
\begin{aligned}
& \text { Respiratory } S A=N_{e s}\left(\left(N_{l}\left(t_{l} * w_{l}\right)\right)+\left(\left(N_{l}-2\right) *\left(h_{p l} * w_{l}\right)\right)\right) \\
& \text { Limited } S A=N_{e s}\left(N_{S}\left(w_{s} * w_{l}\right)\right)
\end{aligned}
$$

\section{Clear:}

$$
\text { Respiratory } S A=N_{e S}\left(\left(N_{l}\left(t_{l} * w_{l}\right)\right)+\left(\left(N_{l}-2\right) *\left(h_{l} * w_{l}\right)\right)\right)
$$

To determine the type of flow experienced at the gill lamellae it was necessary to determine the expected Reynolds regime experienced for the model gill section. Reynolds regimes indicate the extent to which either viscous or inertial forces dominate a given environment (Vogel, 2003). Reynolds number $(R e)$ is determined using the following equation: 


$$
R e=\frac{\rho l v}{\mu}
$$

Where $\rho$ is the density, $\mu$ is the viscosity, and $l$ is the length relevant to the model. The model gill section used for this analysis is assumed to be in fresh water at $20^{\circ} \mathrm{C}$.

Therefore, the viscosity and density of fresh water at $20^{\circ} \mathrm{C}$ were used $(1002 \mathrm{~g} / \mathrm{ms}$ and $998200 \mathrm{~g} / \mathrm{m}^{3}$, respectively). The length scale used for this model was the length through which the water flows (width of the lamellae, $0.0001 \mathrm{~m}$ ). Velocity values used were found in the literature (Graham, 2006; Piiper, Scheid, Perry, \& Hughes, 1986).

Velocities of $0.4 \mathrm{~m} / \mathrm{s}, 0.1 \mathrm{~m} / \mathrm{s}$ and $0.004 \mathrm{~m} / \mathrm{s}$ were used; $0.4 \mathrm{~m} / \mathrm{s}$ is the flow velocity measured just before the gills, $0.1 \mathrm{~m} / \mathrm{s}$ is the flow velocity measured as water exits the gills and $0.004 \mathrm{~m} / \mathrm{s}$ is the flow across the lamellae. Table 2 shows a summary of the calculations.

Table 2.

Reynolds numbers calculated for three flow velocities in freshwater at $20^{\circ} \mathrm{C}$.

\begin{tabular}{|c|c|}
\hline Velocity $(\mathrm{m} / \mathrm{s})$ & $R e$ \\
\hline 0.4 & 0.039 \\
\hline 0.1 & 0.01 \\
\hline 0.004 & 0.00039 \\
\hline
\end{tabular}

Vogel (2003) stated that the Reynolds number at which laminar (viscous) forces are no longer dominant and turbulent (inertial) forces begin to dominate is between 1,000 and 2,000 for flow through a pipe. Further, Vogel stated that at low Reynolds numbers, generally below 10, flow across a solid is completely laminar. When the calculated Reynolds numbers for the model gill section are compared to these benchmarks, it can be assumed that flow across the model gill section is laminar. 
The model gill section described above can be considered a series of surfaces between which water flows. Laminar flow between two surfaces is described by a modification of the Hagen-Poiseuille laminar pipe flow theory (Stevens \& Lightfoot, 1986; Vogel, 2003). This theory described for flow between parallel plates is shown by figure 6.

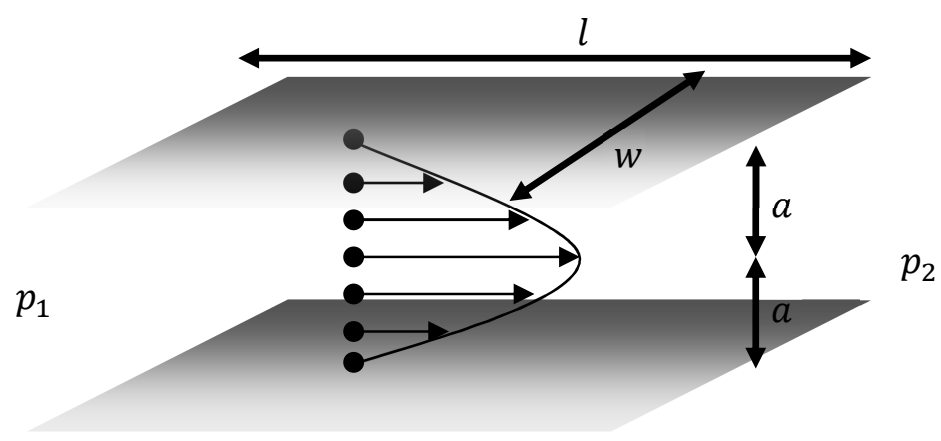

Figure 6. Diagram of the Hagen-Poiseuille theory of laminar flow between two parallel plates. $\boldsymbol{l}$ is the length of the plates, $\boldsymbol{w}$ the width, $\boldsymbol{a}$ is half the distance between the plates and $\boldsymbol{p}_{\mathbf{1}}$ and $\boldsymbol{p}_{\mathbf{2}}$ are the pressures before and after the plates. The parabola describes the velocity gradient. Velocities are slowest near the plates and increase to a maximum at distance, $\boldsymbol{a}$.

Given two parallel surfaces a fixed distance apart, the total flow $(Q)$, maximum flow velocity $\left(V_{\max }\right)$, and average flow velocity $\left(V_{\text {avg }}\right)$ can be given by the following equations:

$$
Q=\frac{\Delta p}{l} * \frac{2 w a^{3}}{3 \mu} \quad V_{\max }=\frac{\Delta p}{l} * \frac{a^{2}}{2 \mu} \quad V_{\text {avg }}=\frac{\Delta p}{l} * \frac{a^{2}}{3 \mu}
$$

Variables are shown in Figure 6, except viscosity $(\mu)$. The pressure gradient was estimated from literature values (Hughes, 1966; Hughes \& Morgan, 1973; Lauder, 1984). Total flow $(Q)$ was calculated for each lamellar space separately in the half and clear gill 
model conditions. Therefore, it was necessary to multiply the total flow by the number of lamellar spaces (nine) in the half and clear gill model conditions. Total flow was then multiplied by the total number of spaces between adjacent filaments (two in this model) for each gill model condition.

These equations show that the total flow and pressure decrease are proportional. It takes a higher pressure to move a flow along the pipe faster (Denny, 1993; Vogel, 2003). These equations also assume that a parabolic velocity profile has formed between the plates. If the model gill section, or "pipe," is too short, or measurements are taken near the beginning of a pipe, then the theory does not work. At the beginning of a pipe, the theory described by Bernoulli for converging streamlines better describes the flow. To test whether or not the model gill section was long enough to assume a parabolic velocity profile, a comparison ratio of Bernoulli to Hagen-Poiseuille dominated factors was used.

$$
\frac{B}{H P}=\frac{\rho v a^{2}}{16 \mu l}
$$

This ratio describes the degree to which one or the other will useful in describing the system (Vogel, 2003). The calculated results are shown in Table 3. 
Table 3

Ratio of Bernoulli to Hagen-Poiseuille influences

\begin{tabular}{cccc}
$\begin{array}{c}\text { Gill Model } \\
\text { Condition }\end{array}$ & Velocity $(\mathrm{m} / \mathrm{s})$ & $\mathrm{a}(\mathrm{m})$ & Ratio \\
\hline Full & 0.4 & $5 \times 10^{-6}$ & $4.15 \times 10^{-6}$ \\
Full & 0.1 & $5 \times 10^{-6}$ & $1.03 \times 10^{-6}$ \\
Full & 0.004 & $5 \times 10^{-6}$ & $4.15 \times 10^{-8}$ \\
\hline Half & 0.4 & $25 \times 10^{-6}$ & $1.04 \times 10^{-4}$ \\
Half & 0.1 & $25 \times 10^{-6}$ & $2.59 \times 10^{-5}$ \\
Half & 0.004 & $25 \times 10^{-6}$ & $1.04 \times 10^{-6}$ \\
\hline Clear & 0.4 & $45 \times 10^{-6}$ & $3.36 \times 10^{-4}$ \\
Clear & 0.1 & $45 \times 10^{-6}$ & $8.41 \times 10^{-5}$ \\
Clear & 0.004 & $45 \times 10^{-6}$ & $3.36 \times 10^{-6}$ \\
\hline
\end{tabular}

Within realistic flows across the lamellae, the Hagen-Poiseuille theory reasonably describes the model gill section. Therefore, the Hagen-Poiseuille equations were used to calculate the total flow, the maximum flow, and the average flow across the model gill section for each condition (full, half, and clear).

To explore further the expected effect of the presence of the ILCM, the effect of differing diffusion distances on oxygen uptake was determined. Fick's law of diffusion describes the diffusion of oxygen through the lamellar surface and into the blood according to the following equation:

$$
M O_{2}=\Delta P O_{2} * K O_{2} *\left(\frac{S A}{d}\right)
$$

Where $M \mathrm{O}_{2}$ is the rate of oxygen diffusion, $\triangle \mathrm{PO} \mathrm{O}_{2}$ is the partial pressure gradient across the lamellar surface, $\mathrm{KO}_{2}$ is the permeation coefficient of oxygen through the lamellar 
surface, $S A$ is the surface area considered within the model and $d$ is the thickness of the medium though which diffusion occurs (Graham, 2006; Malte \& Weber, 1985; Scheid \& Piiper, 1971; Scheid, Hook, \& Piiper, 1986). The rate of oxygen diffusion was calculated separately for two types of gill tissues: the lamellae and the ILCM. Values assigned for thickness of each of these tissues were based on measurements of G. affinis gills and literature ranges (Hughes \& Morgan, 1973; Matey et al., 2008; Piiper et al., 1986; Scheid \& Piiper, 1971). For the ILCM, the average distance a molecule would have to travel through to reach the blood vessels was calculated. The permeation coefficient used was taken from a literature estimate (Hughes, 1966). The permeation coefficient was assumed to be the same for all gill tissues.

The effect differing total flows and flow velocities due to the presence of the ILCM was then determined. Total flow $(Q)$ and standard values of available oxygen were used to calculate the amount of oxygen available for uptake by the model gill section in each condition (full, half and clear). Available oxygen was taken from a standard solubility chart for freshwater. Because gill remodeling is induced by changes in oxygen availability and temperature (Sollid et al., 2003; Sollid et al., 2005), the temperature was assumed to be different for each gill model condition. The temperatures were assumed to as $5^{\circ} \mathrm{C}$ (full), $15^{\circ} \mathrm{C}$ (half), and $25^{\circ} \mathrm{C}$ (clear). The total flow $(Q)$ is the volume of water passing through the entire gill model each second. Using the total flow and the dissolved oxygen concentration, the total amount of available oxygen per second and per minute was calculated. This was then compared to the calculated rate of oxygen uptake $\left(\mathrm{MO}_{2}\right)$ and ranges of oxygen consumption for fish ranging from $0.0223-0.219$ 
$\mu \mathrm{M} / \mathrm{min}$ taken from literature values (Clarke \& Johnston, 1999). To compare values calculated for the model gill section and values of total oxygen consumption from the literature, calculated values were multiplied to represent values for the entire respiratory structure. The model gill section represented almost $1 \%$ of the area of one gill arch. To determine the oxygen uptake of the entire system, the calculated values were divided by this percentage (0.0095), and then multiplied by eight (four gill arches on each side of a fish head).

\section{Results}

\section{Surface Area}

The calculated differences in surface area between each gill model condition were distinct (Table 4). The total surface area of the clear model condition $\left(225,000 \mu \mathrm{m}^{2}\right)$ was one and a half times greater than the half model condition $\left(144,000 \mu \mathrm{m}^{2}\right)$ and just over six times greater than the surface area of the full model condition $\left(36,000 \mu \mathrm{m}^{2}\right)$. More dramatic were the differences in respiratory surface areas between the three conditions. The respiratory surface area of the clear model condition $\left(225,000 \mu \mathrm{m}^{2}\right)$ was almost twice the respiratory surface area of the half model condition $\left(117,000 \mu \mathrm{m}^{2}\right)$ and 25 times the respiratory surface area of the full model condition $\left(9,000 \mu \mathrm{m}^{2}\right)$. 
Table 4.

Results of Surface Area Calculations for Each Gill Model Condition

\begin{tabular}{ccc}
$\begin{array}{c}\text { Model } \\
\text { Condition }\end{array}$ & $\begin{array}{c}\text { Type of Surface } \\
\text { Area }\end{array}$ & $\begin{array}{c}\text { Surface } \\
\text { Area }\left(\boldsymbol{\mu m}^{2}\right)\end{array}$ \\
\hline \multirow{3}{*}{ Full } & Total & 36,000 \\
& Respiratory & 9,000 \\
& Limited & 27,000 \\
\hline \multirow{2}{*}{ Half } & Total & 144,000 \\
& Respiratory & 117,000 \\
& Limited & 27,000 \\
\hline \multirow{2}{*}{ Clear } & Total & 225,000 \\
& Respiratory & 225,000 \\
\hline
\end{tabular}

\section{Flows through gill model conditions}

The differences in total flow and velocity between each gill model condition were quite dramatic (Table 5). The clear model condition $\left(1.95 \times 10^{-4} \mathrm{~mL} / \mathrm{min}\right)$ had six times greater volume of water passing through each second than the half model condition $\left(3.34 \times 10^{-5} \mathrm{~mL} / \mathrm{min}\right)$ and almost 550 times greater volume of water passing through each second than the full model condition $\left(3.56 \times 10^{-7} \mathrm{~mL} / \mathrm{min}\right)$. The maximum and average velocity of water passing though the clear model condition $(300.50 \mu \mathrm{m} / \mathrm{s}$ and 200.33 $\mu \mathrm{m} / \mathrm{s})$ were three times faster than through the half model condition $(92.75 \mu \mathrm{m} / \mathrm{s}$ and $61.83 \mu \mathrm{m} / \mathrm{s})$ and 80 times faster than through the full model condition $(3.71 \mu \mathrm{m} / \mathrm{s}$ and $2.47 \mu \mathrm{m} / \mathrm{s}$ ). At these velocities, it would take water entering the lamellar space less than one second to travel across the lamellae in the clear model condition. It would take about two seconds in the half model condition. The most striking result was that at the velocity 
calculated, it would take almost a minute for water to travel across the lamellae in the full model condition.

Table 5.

Calculated Values of Hagen-Poiseuille Flow and Velocity for Each Gill Model Condition

\begin{tabular}{cccccc}
$\begin{array}{c}\text { Model } \\
\text { Condition }\end{array}$ & $\begin{array}{c}\mathbf{Q} \\
(\mathbf{m L} / \mathbf{m i n})\end{array}$ & $\begin{array}{c}\mathbf{V}_{\max } \\
(\boldsymbol{\mu m} / \mathbf{s})\end{array}$ & $\begin{array}{c}\mathbf{t}_{\max } \\
(\mathbf{s e c})\end{array}$ & $\begin{array}{c}\mathbf{V}_{\text {avg }} \\
(\boldsymbol{\mu m} / \mathbf{s})\end{array}$ & $\begin{array}{c}\mathbf{t}_{\text {avg }} \\
(\mathbf{s e c})\end{array}$ \\
\hline Full & $3.56 \times 10^{-7}$ & 3.71 & 40.43 & 2.47 & 60.65 \\
Half & $3.34 \times 10^{-5}$ & 92.75 & 1.62 & 61.83 & 2.42 \\
Clear & $1.95 \times 10^{-4}$ & 300.50 & 0.50 & 200.33 & 0.75
\end{tabular}

Note: $t_{\max }$ and $t_{a v g}$ are the fastest time and the average time it takes for water entering the lamellar space to cross the entire lamella, respectively.

\section{Rate of oxygen diffusion}

The rate of oxygen diffusion differed drastically between each gill model condition (Table 6). The total rate of oxygen diffusion for the clear model condition $(6.610 \mu \mathrm{M} / \mathrm{min})$ was almost double that of the half model condition $(3.618 \mu \mathrm{M} / \mathrm{min})$ and almost 15 times that of the full model condition $(0.442 \mu \mathrm{M} / \mathrm{min})$. The differences in rate of oxygen uptake between respiratory surfaces (the lamellae) and limited respiratory surfaces (ILCM) were also considerable. Within the full gill model condition, the limited respiratory surface area $\left(27,000 \mu \mathrm{m}^{2}\right)$ was three times that of the respiratory surface area $\left(9,000 \mu \mathrm{m}^{2}\right)$. However, the rate of oxygen diffusion was still higher for the respiratory surface area $(0.263 \mu \mathrm{M} / \mathrm{min})$ than for the limited respiratory surface area $(0.179$ $\mu \mathrm{M} / \mathrm{min})$. 
Table 6.

Calculated Rates of Oxygen Uptake Within Each Gill Model Condition

\begin{tabular}{ll}
$\begin{array}{c}\text { Model } \\
\text { Condition }\end{array}$ & $\begin{array}{c}\mathrm{MO}_{2} \\
(\mu \mathrm{M} / \mathrm{min})\end{array}$ \\
\hline Full & \\
$\begin{array}{r}\text { Total } \\
\text { Respiratory } \\
\text { Limited }\end{array}$ & 0.442 \\
Half & 0.263 \\
Total & 3.618 \\
Respiratory & 3.439 \\
Limited & 0.179 \\
Clear & 6.610
\end{tabular}

\section{Oxygen uptake}

There were distinct differences in available oxygen between the three gill model conditions (Table 7$)$. The available oxygen for the clear gill model condition $\left(5.48 \times 10^{-5}\right.$ $\mu \mathrm{M} / \mathrm{min})$ was almost five times that of the half model condition $\left(1.118 \times 10^{-5} \mu \mathrm{M} / \mathrm{min}\right)$ and over 300 times that of the full model condition $\left(1.622 \times 10^{-7} \mu \mathrm{M} / \mathrm{min}\right)$. The available oxygen determined by the total flow through the model gill section was minute compared to the potential diffusion rate $\left(\mathrm{MO}_{2}\right)$ of oxygen across the respiratory and limited respiratory surfaces. The potential diffusion rate represents the diffusion of oxygen across the entire model surface area unlimited by flow. The potential diffusion rate of oxygen was $1.2 \times 10^{5}$ times, $3.2 \times 10^{5}$ times, and $2.7 \times 10^{6}$ times the available oxygen in the clear, half, and full model conditions, respectively. However, when compared to oxygen consumption from literature values, $0.0223-0.219 \mu \mathrm{M} / \mathrm{min}$ (Clarke \& Johnston, 1999), the potential diffusion rate across the entire respiratory structure was far greater than 
what would actually be needed to sustain life. The total available oxygen for the clear model condition $(0.046 \mu \mathrm{M} / \mathrm{min})$ fell within the range of oxygen consumption (oxygen needed by a fish). The total available oxygen for the half model condition $(0.0094$ $\mu \mathrm{M} / \mathrm{min})$ and the full model condition $(0.00014 \mu \mathrm{M} / \mathrm{min})$ did not meet the range of oxygen consumption.

Table 7.

Oxygen diffusion rate and available oxygen within the model gill section and for the total estimated respiratory surface.

\begin{tabular}{ccccc}
$\begin{array}{c}\text { Model } \\
\text { Condition }\end{array}$ & $\begin{array}{c}\mathrm{MO}_{2} \\
(\mu \mathrm{M} / \mathrm{min})\end{array}$ & $\begin{array}{c}\text { Available } \mathrm{O}_{2} \\
(\mu \mathrm{M} / \mathrm{min})\end{array}$ & $\begin{array}{c}\text { Total } \\
\mathrm{MO}_{2} \\
(\mu \mathrm{M} / \mathrm{min})\end{array}$ & $\begin{array}{c}\text { Total } \\
\text { Available } \mathrm{O}_{2} \\
(\mu \mathrm{M} / \mathrm{min})\end{array}$ \\
\hline Full & 0.442 & $1.622 \times 10^{-7}$ & 372.91 & 0.00014 \\
Half & 3.618 & $1.118 \times 10^{-5}$ & $3,044.89$ & 0.0094 \\
Clear & 6.610 & $5.48 \times 10^{-5}$ & $5,566.82$ & 0.046
\end{tabular}

Note: $\mathrm{MO}_{2}$ and avalable $\mathrm{O}_{2}$ are the values calculated for the model gill section. Total $M \mathrm{O}_{2}$ and Total avalable $\mathrm{O}_{2}$ are the values estimated over an entire gill system.

\section{Discussion}

The presence of the interlamellar cell mass had a considerable effect on the respiratory function and capacity of model gill section. The surface area, flow (total volume and velocities), and rate of oxygen uptake were all dramatically different for each gill model condition. The presence of the interlamellar cell mass reduced the respiratory surface area, reduced the space available for flow though the gill model, and increased the water-blood diffusion distance.

The differences in surface area that were built into the model gill section resembled values measured in previous studies. The difference in surface area was one 
and a half times greater for the clear model condition than for the half model condition and six times greater for the clear model condition than for the full model condition. These were similar to literature values. For the crucian carp, Carassius carassius, there was a seven-fold difference in surface area between individuals in normoxic and hypoxic water (Sollid et al., 2003). During gill remodeling, the gills of $C$. carassius change from having an ILCM completely filling the interlamellar space in normoxic waters to the total loss of the ILCM in hypoxic waters. The difference in the clear gill model condition and the full gill model condition mimicked this difference. For the Lake Qinghai scaleless carp, Gymnocypris prezewalskii, the difference in surface area between individuals in normoxic and hypoxic waters was two-fold (Matey et al., 2008). The change during gill remodeling for $G$. prezewalskii is not as large as for $C$. carassius. The gills of $G$. prezewalskii change from having the interlamellar space nearly half-filled with the interlamellar cell mass in normoxic waters, to a much-reduced interlamellar cell mass in hypoxic waters. The difference in the half model condition and the clear model condition mimicked this difference.

The sizable differences in total flow and velocity of water between the three gill model conditions showed that the interlamellar cell mass presented a significant barrier to flow across the model gill section. When the ILCM was present, the physical space through which water could flow was reduced. This reduced space meant that for a set pressure, the amount of water able to pass over the model gill section was limited and the speed with which water could pass was reduced. Velocities were reduced to a level that would be physiologically ineffectual. In the full model gill condition, it would take a 
minute for water to pass through. This model assumed that the change in pressure over the gill for the three gill model conditions was the same. In reality, this pressure changes as a fish goes through a buccal pumping cycle (Helfman et al., 2009). In addition, to compensate for the increased barrier due to the presence of the interlamellar cell mass, a fish could increase the pressure of water moving over the gill to increase total flow and flow velocities. This method of compensating for the presence of the interlamellar cell mass would be relatively simple for a fish to achieve. Fishes have several other mechanisms for compensating for the barrier to flow presented by the ILCM. For the model gill section, lamellar and filament thicknesses, blood perfusion, and gill microstructures were also assumed to the same for each model gill condition. In reality, these can be varied in response to environmental conditions. Oxygen uptake could be increased by reducing lamellar and filament thicknesses, by increasing blood perfusion across the gill system, and by changing surface area of individual cells (gill microstructure) (Evans et al., 2005; Wilson \& Laurent, 2002).

Differences in total flow and flow velocities over gills with and without the interlamellar cell mass have not been examined, theoretically or experimentally, in the literature. The theoretical examination performed here provides insight into the consequences of the presence of the ILCM. Total flow and flow velocities both differ dramatically with changes to the ILCM. Measuring flow differences between gills with and gills without the interlamellar cell mass in situ or in vivo would be an interesting and valuable exploration. An in vivo exploration might also be able to compare the energy costs of pumping water over gills with and without the interlamellar cell mass. 
The interlamellar cell mass is also a significant barrier to oxygen diffusion across the lamellar surface. The rate of oxygen uptake was considerably faster for the clear model condition than for the half and full model conditions. Also, overall rates of oxygen uptake were faster for respiratory surfaces than for surfaces limited by the interlamellar cell mass, even when the total respiratory surface area was much smaller than the limited respiratory surface area (such as in the full model). When compared to literature values, the rates of oxygen uptake estimated by this model were somewhat inflated. This is because of the assumptions made in the examination of the model gill section. In reality, the adaptations for oxygen uptake are much more complex. However, the differences predicted by this theoretical examination, although not as pronounced, have been observed in the literature. In a study conducted by Sollid, Weber and Nilsson (2005), the rate of oxygen uptake increased temperature for C. carassius at $10^{\circ} \mathrm{C}, 15^{\circ} \mathrm{C}$, $20^{\circ} \mathrm{C}$. At $10^{\circ} \mathrm{C}$, the interlamellar spaces were filled with the interlamellar cell mass. At $15^{\circ}$ and $20^{\circ} \mathrm{C}$, the interlamellar spaces were moderately filled and half filled with the interlamellar cell mass, respectively. At $25^{\circ} \mathrm{C}$, the interlamellar spaces were almost completely clear. The fastest rate of oxygen uptake (for individuals in $25^{\circ} \mathrm{C}$ ) was 1.7 times, 2.4 times, and 5.4 times the rates for individuals in the $20^{\circ} \mathrm{C}, 15^{\circ} \mathrm{C}$, and $10^{\circ} \mathrm{C}$ treatments, respectively.

The estimated available oxygen for each gill model condition was significantly different. The available oxygen in each gill model condition was based on the total flow through the gill model calculated for each condition. Available oxygen was less for the half model condition and for the full model condition than for the clear model condition, 
because less water was able to flow though the smaller spaces. A live fish would be able to compensate for the presence of the interlamellar cell mass and the resulting smaller spaces through which water would flow. A live fish would be able to increase pressure of buccal pumping or decrease blood-water diffusion distance (thinning of the lamellae and the filament) (Farrell, Daxboeck, \& Randall, 1979; Farrell, Sobin, Randall, \& Crosby, 1980).

The presence of the interlamellar cell mass had a significant effect on flow through and oxygen uptake of the model gill section. Although fishes have means of compensating for these effects, the energy costs could be significant. However, the difficulties presented by the interlamellar cell mass would be offset by the favorable conditions when the interlamellar cell mass develops. The interlamellar cell mas was present in normoxic waters and cold temperatures (with higher oxygen concentrations) (Matey et al., 2008; Sollid et al., 2003; Sollid et al., 2005). Several studies have explored the metabolic effects and costs of gill remodeling (Brauner et al., 2008; LeBlanc, Wood, Fudge, \& Wright, 2013; Matey et al., 2008; Mitrovic \& Perry, 2009; Sollid et al., 2005; Turko, Cooper, \& Wright, 2012; Tzaneva, Gilmour, \& Perry, 2011) with interesting results. Studies have found that uptakes in oxygen and excretion of carbon dioxide were significantly affected by gill remodeling similar to calculated estimates for the model gill section. However, no significant effect of gill remodeling on metabolic measures has been found. It would seem that the costs of gill remodeling are offset sufficiently by the benefits found within each condition; reduced ion regulation in normoxic waters and increased oxygen uptake in hypoxic or warmer waters. 
PART 2: EXPERIMENTAL EXPLORATION OF GILL REMODELING OF GAMBUSIA AFFINIS IN RESPONSE TO SALINITY AND TEMPERATURE CHANGES 


\section{Introduction}

The lamellar surface is the primary site of gas exchange in most fishes (Evans et al., 2005; Graham, 2006; Wilson \& Laurent, 2002), and has, therefore, been the focus of many studies. Gray (1954) was the first to do a broad study of how gill surface area (measured as whole gill surface area) differed among fishes with differing life histories. He found that active, pelagic fishes tended to have relatively larger gill surface areas as compared to more sluggish, benthic fishes. Many subsequent studies have confirmed a correlation between modes of life (with differing oxygen demands) and differing respiratory surface areas (Davis, 1971; De Jager, Smit-Onel, Videler, Van Gils, \& Uffink, 1977; Hughes \& Morgan, 1973). Fishes with higher metabolic rates seem to have relatively larger respiratory surface area. Also, hypoxia-tolerant fishes seem to have relatively larger respiratory surface areas (Chapman, Galis, \& Shinn, 2000; Chapman \& Hulen, 2001; Narahara et al., 1996; Scott et al., 2008). In a class study, a similar correlation was found with sculpin species (family Cottidae) living at different tidal heights (Douglas, 2006). Species living in higher intertidal pools (which may become increasingly hypoxic) had a significantly larger lamellar surface area relative to sculpin species living in lower intertidal pools (which do not become hypoxic).

The ability of a fish to obtain oxygen is directly related to its survivability. Thus, adaptations that enhance the uptake of oxygen (such as higher surface area) should be highly advantageous and likely strongly selected for. However, there are disadvantages and limits to having a large respiratory surface area. A fish's respiratory surface area is likely to be a compromise between increasing oxygen uptake and minimizing ion and 
water loss across the gills. This is called the "Osmoregulatory Compromise" (Gonzalez \& McDonald, 1992). There are possibly large metabolic costs associated with the maintenance of ion concentration and water within a fish's body. Freshwater fishes must expend energy to maintain ion concentrations as they lose ions to the surrounding water. Marine fishes must expend energy to maintain water concentrations, as it is lost to the surrounding seawater. Bæuf and Payan (2001) estimated that the cost of maintaining these balances is between 10 and $50 \%$ of a fish's total energy budget. As a point of clarification, note that the process of maintaining these balances is termed either ionoregulation or osmoregulation. These terms are generally used interchangeably, the former often used when discussing freshwater fishes and the latter when discussing marine fishes. As Gambusia affinis is a freshwater fish, the term ionoregulation is used in this study.

Besides the possible costs of ion regulation, there are other disadvantages of large gills. These include greater exposure to toxins, parasites, and pathogens, and potential greater susceptibility to damage (Nilsson, 2007). Limited space within the buccal and opercular cavities and the potential need for streamlining might also limit the size of gills, and therefore respiratory surface area.

Fishes have several mechanisms for dealing with the competing advantages and disadvantages of large gills. Many (if not all) fishes can alter the volume and/or the frequency of buccal pumping, increasing the amount of fresh, oxygenated water exposed to the gills (Cailliet, Love, \& Ebling, 1996). Many fishes can also alter the functional respiratory surface area by varying the amount of blood supplied to the respiratory 
surface (Graham, 2006; Gonzales, Katoh, \& Ishimatsu, 2008; Huang, Lee, \& Lin, 2008). Some fishes can alter the cellular make-up of the gill surface by changing the number of mitochondria-rich cells present at the surface and/or by changing the thickness of epithelial cells (Da Costa, Pedretti, Schmitz, Perry, \& Fernandes, 2007; Fernandes \& Perna-Martins, 2002; Stensløkken, Sundin, \& Nilsson, 1999).

Finally, researchers have discovered another mechanism for dealing with competing ionoregulatory and oxygen uptake demands. Researchers have found five species that have the ability to remodel their respiratory surface area in response to changing environmental conditions. This ability was first discovered in the crucian carp, Carassius carassius (Sollid et al., 2003). Researchers found that a change in respiratory surface area can be induced by exposure to hypoxic waters in C. carassius, in Carassius auratus (goldfish), and in Gymnocypris prezewalskii (Lake Qinghai scaleless carp) (Matey et al., 2008; Sollid et al., 2005, 2003). Temperature changes were also shown to induce a change in C. carassius and C. auratus (Sollid et al., 2005). Another study (Ong et al., 2007), found that the amphibious Kryptolebias marmoratus (mangrove killifish) is also able to remodel respiratory surface area in response to aerial exposure. In his review of these discoveries, Nilsson (2007), also noted a similarity between the change in respiratory surface area due to the building up and degradation of the ILCM, and the proliferation of cells in response to aluminum toxicity in Salvelinus fontinalis (brook trout) described in 1991(McDonald, Wood, et al., 1991).

The discovery that the ability to remodel gills is present in fishes from two, possibly three, distantly-related orders of fishes raises several evolutionary questions. 
Did this ability evolve independently in different orders, convergent evolution, or is it a trait shared by the distant ancestor to these two groups? How many other orders of fishes have this ability? Is this ability evolutionarily difficult or is it relatively easy for a population to develop this trait in response to environmental conditions? Is this ability only present in freshwater species?

To address these questions, a species with an interesting relationship to previously studied species was chosen for this study. This species, Gambusia affinis (mosquitofish) is a relative of the, K. marmoratus being within the same order, Cyprinofontiformes. G. affinis displays several characteristics that may be indicative of an ability to remodel their gills. G. affinis is a very hardy fish often used in mosquito control. They are found in fresh and brackish water, and have been found to be able to survive a wide range of temperatures (Chervinski, 1983; Itoh, 2006; Otto, 1973). The presence of the ability to remodel gills in G. affinis would indicate a possible widespread presence of this ability within the Cyprinodontiformes. Because they are not closely related, it is also important to understand if the same environmental conditions could trigger gill remodeling in a cypriniform and a cyprinodontiform fish. Because G. affinis is not amphibious, if it exhibited the ability to remodel its gills, it would most likely be in response to changes in temperature and/or oxygen concentrations rather than aerial exposure. This would support either a link between the ability of fishes in the orders Cyprinidontiformes and the Cypriniformes, or the idea that this ability is relatively easy to evolve, or strongly selected for in certain conditions.

Gambusia affinis was also chosen for this study because of its unusual tolerance 
of various salinities (Al-Daham \& Bhatti, 1977; Chervinski, 1983). Previous studies have explored temperature, hypoxia, exercise, and aerial exposure as triggers of gill remodeling (Brauner et al., 2008; Matey et al., 2008; Ong et al., 2007; Sollid et al., 2003; Sollid et al., 2005). No research has explored changes in salinity as a trigger for gill remodeling, as most of the species studied are not tolerant of large changes in salinity. If, as has been hypothesized, gill remodeling is a mechanism for dealing with competing ionoregulatory and respiratory needs, changes in salinity may also be a trigger.

\section{Method}

Experimental protocol was reviewed and approved by SJSU IACUC \#924.

\section{Fish acquisition and holding}

Gambusia affinis (approximately 450 individuals) were collected as a donation from the Santa Clara County Vector Control District in San José California. They were transported from Santa Clara County Vector Control District to San José State University (SJSU) in large coolers with aerated San José tap water. Upon arrival to SJSU, they were transferred into one of three large ( $>35$ gallon) holding aquaria with chemically conditioned (AquaSafe, Tetra Aqua, Melle, Germany) San José tap water. Prior to obtaining the G. affinis, each holding aquarium was fitted with a filter, a water heater, and a thermometer. Aquaria were allowed to stabilize to 17 degrees Celsius prior to obtaining G. affinis specimen. Once in the holding tanks, specimen were allowed to acclimate for two weeks prior to exposure to experimental conditions. The holding and experimental aquaria were kept in a lab with a $12 \mathrm{~h}: 12 \mathrm{~h}$ Light:Dark regime. Water quality 
$\left(\mathrm{pH}, \mathrm{NO}_{2}{ }^{-}, \mathrm{NO}_{3}{ }^{-}, \mathrm{NH}_{3}\right)$ was monitored throughout the study using a Freshwater Master Test Kit (Mars Fishcare North America, Chalfont, PA). G. affinis were fed daily with commercial fish food (TetraMin, Tetra Aqua, Melle, Germany).

\section{Experimental procedure - temperature and salinity exposure}

Eight experimental aquaria were prepared to test gill response to temperature and salinity. These ten-gallon aquaria were randomly arranged on a large metal rack.

Aquarium numbers were assigned based on the experimental conditions (Table 1). Aquaria 1-4 varied in temperature. Aquaria 6-8 varied in salinity. Aquarium 5 served as a control for both temperature and salinity experiments as conditions within aquarium 5 were identical to the holding aquaria. The experiment was run twice to avoid pseudoreplication.

Table 1

Conditions within experimental aquaria

\begin{tabular}{ccc}
\hline Aquarium \# & $\begin{array}{c}\text { Temperature } \\
\left({ }^{\circ} \mathbf{C}\right)\end{array}$ & $\begin{array}{c}\text { Salinity } \\
\text { (PSU) }\end{array}$ \\
\hline 1 & 8 & 0 \\
2 & 12 & 0 \\
3 & 20 & 0 \\
4 & 26 & 0 \\
5 & 17 & 0 \\
6 & 17 & 5 \\
7 & 17 & $15-10$ \\
8 & 17 & $20-15$
\end{tabular}

Note. Conditions within aquaria 7 and 8 were modified for the second round of the main experiments. 
Aquaria 1 and 2 were fitted with a cooling system. The cooling system consisted of plastic tubing and an aquatic pump that ran the water from the aquaria through a large chest freezer and back into the aquaria. Temperature was controlled by the length of plastic tubing placed in the freezer. All other aquaria were fitted with adjustable heaters. Salinity was varied in aquaria $6-8$ by adding commercial salt mix (Instant Ocean, United Pet Group, Blacksburg, VA). All experimental aquaria were fitted with a thermometer to monitor temperature. Additionally, a YSI meter was used to monitor temperature, salinity (conductivity), and oxygen concentrations within the experimental aquaria. Conditions within the experimental aquaria were stabilized as G. affinis individuals acclimated within the holding aquaria.

To begin the experiment, G. affinis individuals were transferred from the holding aquaria and randomly distributed among the eight experimental aquaria. At this time, eight individuals were sacrificed from the holding tanks as a reference for time zero. To determine how quickly remodeling might occur and how it changes over time individuals were sacrificed at six different times. Three G. affinis individuals from each experimental aquarium were sacrificed after one hour, $6 \mathrm{hr}, 12 \mathrm{hr}, 24 \mathrm{hr}$, three days and five days. Any remaining G. affinis individuals within the experimental aquaria were returned to the holding aquaria and allowed to re-acclimate.

The experimental aquaria were then randomly redistributed on the large metal rack in preparation for a second run of the experiment. Aquarium numbers (with their corresponding conditions, Table 1) were kept the same, with the exception of aquaria seven and eight. After $24 \mathrm{hr}$, the remaining G. affinis individuals in tank eight had died. 
Although G. affinis has been shown to be tolerant of high salt concentrations (35 psu), they were not able to tolerate the abrupt movement from fresh to 25 psu water (Chervinski, 1983; Itoh, 2006). Salinity in tanks 7 and 8 was reduced (see Table 1) to maintain a range of salinity while reducing the risk of early death. Temperature and salinity experiments were then repeated according to the conditions listed in Table 1. G. affinis individuals were sacrificed at the same six times (after one hour, $6 \mathrm{hr}, 12 \mathrm{hr}, 24 \mathrm{hr}$, three days and five days).

To sacrifice the G. affinis, individuals were anesthetized with $100 \mathrm{mg} / \mathrm{L}$ MS 222, restrained, and sacrificed by decapitation with a sharp scalpel. For each individual, sex was determined; fish length and weight were recorded. From each G. affinis individual, the second gill arch was removed on the left and right sides. Tissues from the left side were prepared for viewing with light microscopy. Tissues from the right side were prepared for viewing with scanning electron microscopy (SEM).

\section{Experimental procedure - determining size effects}

After a preliminary look at the gill tissues, it appeared that the size of G. affinis could have a significant effect on the extent of gill remodeling. To test this, a size comparison experiment was conducted. Four aquaria were prepared, three at eight degrees Celsius and one control tank at 17 degrees Celsius. G. affinis individuals of varying sizes were randomly distributed from the holding tanks into the four aquaria. $G$. affinis individuals were sacrificed, measured, and tissues taken after $12 \mathrm{hr}$ according the procedures described above. 


\section{Histological methods: preparation for light microscopy}

Gill tissues removed from the left side of each $G$. affinis individual were immediately placed in a solution of $2 \%$ glutaraldehyde for $24 \mathrm{hr}$. Glutaraldehyde $\left(\mathrm{OHCCH}_{2} \mathrm{CH}_{2} \mathrm{CH}_{2} \mathrm{CHO}\right)$ fixes tissues by cross-linking proteins with its two terminal aldehyde groups. Glutaraldehyde also reacts to some extent with lipids, carbohydrates, and nucleic acids. The result is the tissue/ cellular constituents held in place by a meshwork of glutaraldehyde molecules (Bozzola \& Russell, 1991). After primary fixation in glutaraldehyde, tissues were rinsed in $100 \mathrm{mM}$ phosphate buffer to remove any free, unreacted glutaraldehyde from the tissue. Tissues were then post-fixed in 1\% osmium tetroxide $\left(\mathrm{OsO}_{4}\right)$ for approximately $15 \mathrm{~min}$ and removed once they turned a light brown color, indicating sufficient penetration. Osmium tetroxide additionally fixes tissues by binding with lipids (Bozzola \& Russell, 1991). Once post-fixed, tissues were dehydrated in a series of 5 min graded ethanol baths, $70 \%, 80 \%, 90 \%, 95 \%$, and $100 \%$ ethanol (95\% and 100\% ethanol baths were repeated two times each). Dehydrated tissues were rinsed in propylene oxide $\left(\mathrm{CH}_{3} \mathrm{CHCH}_{2} \mathrm{O}\right)$ four times for $15 \mathrm{~min}$ in preparation for resin embedding. The embedding process was completed in two parts: infiltration of the resin into the tissues (replacing the dehydrant, ethanol) and embedding of the tissue in a resin mold. The resin used was a standard Epon 812 epoxy resin mix. Infiltration of the resin into the tissues was begun by transferring tissues from propylene oxide into a 1:1 mix of propylene oxide and resin for one hour. This was followed by another hour in a 1:2 mix of propylene oxide and resin. Finally, tissues were transferred to pure resin and allowed to sit overnight. Fresh resin was made and piped into silicon molds. Tissues 
were placed such that sections could be cut parallel to the long axis of the gill filaments. Once placed in molds, tissues and resin were cured at $60^{\circ} \mathrm{C}$ for $24 \mathrm{hr}$. Cured resin blocks were trimmed using a sharp razor blade and a Dremmel Tool to remove excess resin over the surface of the tissues. After trimming the resin blocks, semi-thin $(1 \mu \mathrm{m})$ sections were

prepared with an ultramicrotome (Leica Microsystems, Wetzlar, Germany). Cut sections were transferred to glass slides and stained with $0.5 \%$ methylene blue.

Stained slides were examined with a Leica light microscope fitted with a calibrated digital camera (Leica Microsystems, Wetzlar, Germany). Multiple images at 04X, 10X, and 40X magnification were taken.

\section{Histological methods: preparation for SEM}

Gill arches taken from the right side of individual G. affinis were prepared for viewing with scanning electron microscopy (SEM). Primary fixation, post fixation and dehydration were conducted as described above for light microscopy. After dehydration, gill tissues were critical-point dried using liquid $\mathrm{CO}_{2}$ in a Polaron E3000 critical point dryer (Polaron, Quorum Technologies, Newhaven, East Sussex, United Kingdom). Dried gill tissues were mounted on aluminum stubs, and sputter coated with gold -palladium mix. Finally, gill tissues were examined and multiple pictures were taken with a Hitachi scanning electron microscope (Hitachi High Technologies Corp., Schaumburg, IL).

\section{Morphometry}

Images taken with light microscopy (LM) and scanning electron microscopy (SEM) were imported into Image J software (Rasband, 2010). Using Image J, various gill parameters were measured for each individual. These parameters included: (a) 
protruding lamellar height in contact with surrounding water (by LM); (b) lamellar thickness (by LM and by SEM); (c) thickness of filament epithelium (by LM); (d) basal length of the protruding part of the lamellae (by SEM); (e) height of the interlamellar cell mass (by LM); (f) width between lamellae (by LM); (g) length of the longest filament (by SEM); (h) length of the shortest filament (by SEM); and the number of filaments attached to the gill arch per $500 \mu \mathrm{m}$ (by SEM). Each parameter (excluding the last three) was measured on each individual three times at randomized lamellae. Values of these parameters used for data analysis represent a mean of the three separate measurements taken.

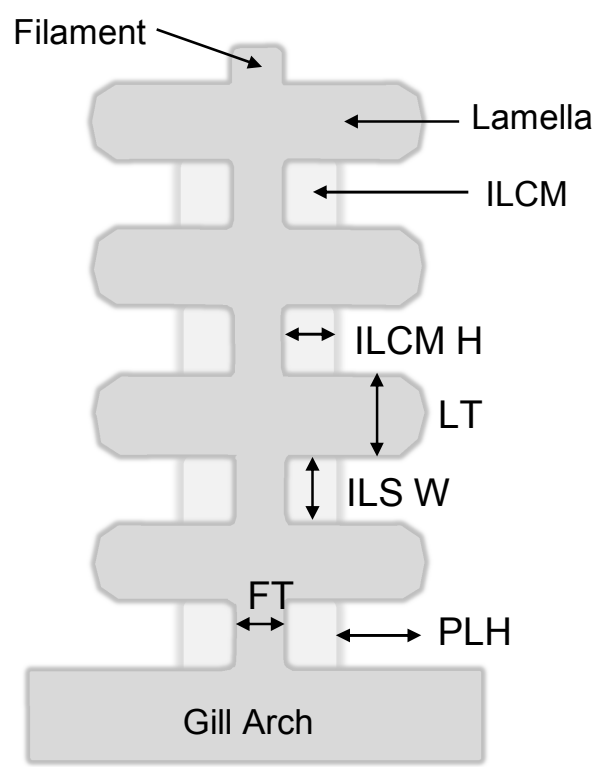

Figure 1. Diagram of a gill filament showing morphometric measurements taken. Abbreviations: Interlamellar cell mass (ILCM), protruding lamellar height (PLH), lamellar thickness (LT), filament thickness (FT), interlamellar cell mass height (ILCM H), and interlamellar space width (ILS W). 
Mean cross-sectional surface area (CSSA) was calculated using the height of the interlamellar cell mass (ILCMH) and the width between lamellae (LW) where CSSA = ILCMH x LW. Using a formula proposed by Sollid, De Angelis, Gunderson, and Nilsson (2003), the surface area of the protruding lamella (respiratory surface area) was calculated. Three measurements were used for this calculation: basal length of the protruding lamellae (l), protruding lamellar height (h), and lamellar thickness (t; LM measurement was used). The respiratory surface area (a) was calculated where $a=p l ; p$ is the ellipse perimeter formula divided by 2 :

$$
p=\frac{2 \pi \sqrt{1 / 2\left(r^{2}+h^{2}\right)}}{2}
$$

and $r=\frac{t}{2}$.

\section{Data Analysis}

Determination of size effects. To determine if fish size affected the extent to which gill remodeling occurred, linear regression analyses were performed for the different size measurements as predictors of surface area. As described above, four different size measurements (length, weight, length of longest filament, and length of shortest filament) were taken for each individual sampled. Measurements that were significant predictors of surface area were then compared using principal components analysis (PCA). Correlated measurements were then reduced using an eigenvalue of one, to one component (fish size component) to use as a covariate in further analyses. The prediction ability of the extracted fish size component was examined using linear regression analysis. 
Main effects of temperature and salinity. Analysis of data was conducted on salinity and temperature separately as there was no measure of interaction between them. Although data were analyzed separately, statistical analysis of temperature and salinity data were generally the same. As outlined above, the main experimental procedure was run twice. For both temperature and salinity, one-way ANOVAs were performed for all relevant morphological variables to determine if there were any significant differences between the two rounds of the experiment. Data was split by either temperature or salinity as to compare the two aquaria with the same treatment from the two rounds of the experiment. The significance level was set at $p=.05$. The null hypothesis was that there was no difference between the two experiments (no effect of individual aquarium). When the null was rejected for any case, aquarium was analyzed nested within temperature or salinity. When the null was accepted for all cases, data from both rounds of the experiment were combined.

To determine the effect of temperature and salinity on measured and calculated morphometric variables, two-way ANCOVAs were performed for each variable. The significance level for all two-way ANCOVAs, was set at $p=.05$. Fish size component was used as the covariate, all means reported represent means adjusted for the fish size component. Interaction between time and temperature and between time and salinity were examined for all two-way ANCOVAs. When the interaction between time and temperature or between time and salinity was significant, simple main effects were examined. When no significant interaction was found, values of the between subjects effects were reported directly from the two-way ANCOVA output and Bonferroni post 
hoc tests were performed.

Outliers were examined using the residuals of the multi-way analysis and a plot of predicted verses residuals. Homogeneity of variances was assessed by Levene's Test of Homogeneity of Variance $(p>0.05)$. For the temperature treatment, it was determined that four outliers (out of 178 measured individuals) were present in the analysis and that homogeneity of variances was not met for two-way ANCOVAs of several variables.

The Q-Q plots and predicted values versus residuals with and without the outliers for the analysis of respiratory surface area in the temperature experiment are given in Figure 2. In the plot of residuals verses predicted values of respiratory surface area, inequality of variances can be seen. Variance for lower values is less than that of higher values (megaphone shaped). When these four outliers were removed, equality of variance was met for all two-way ANCOVA analyses except the analysis of filament thickness $(p=0.014)$. It was determined that the four outliers would be removed for all further analyses. For the analysis of filament thickness it was determined that the twoway ANCOVA would still be appropriate as ANOVA analyses are fairly robust to deviations in homogeneity of variance when sample sizes are equal (Underwood, 1981).

For the salinity treatments, it was determined that three outliers (out of 130 measured individuals) were present in the analysis. Homogeneity of variances was met for all cases, however the three outliers had a disproportionate effect on variance. With the outliers removed homogeneity was increased. These outliers were removed from all further analyses. 


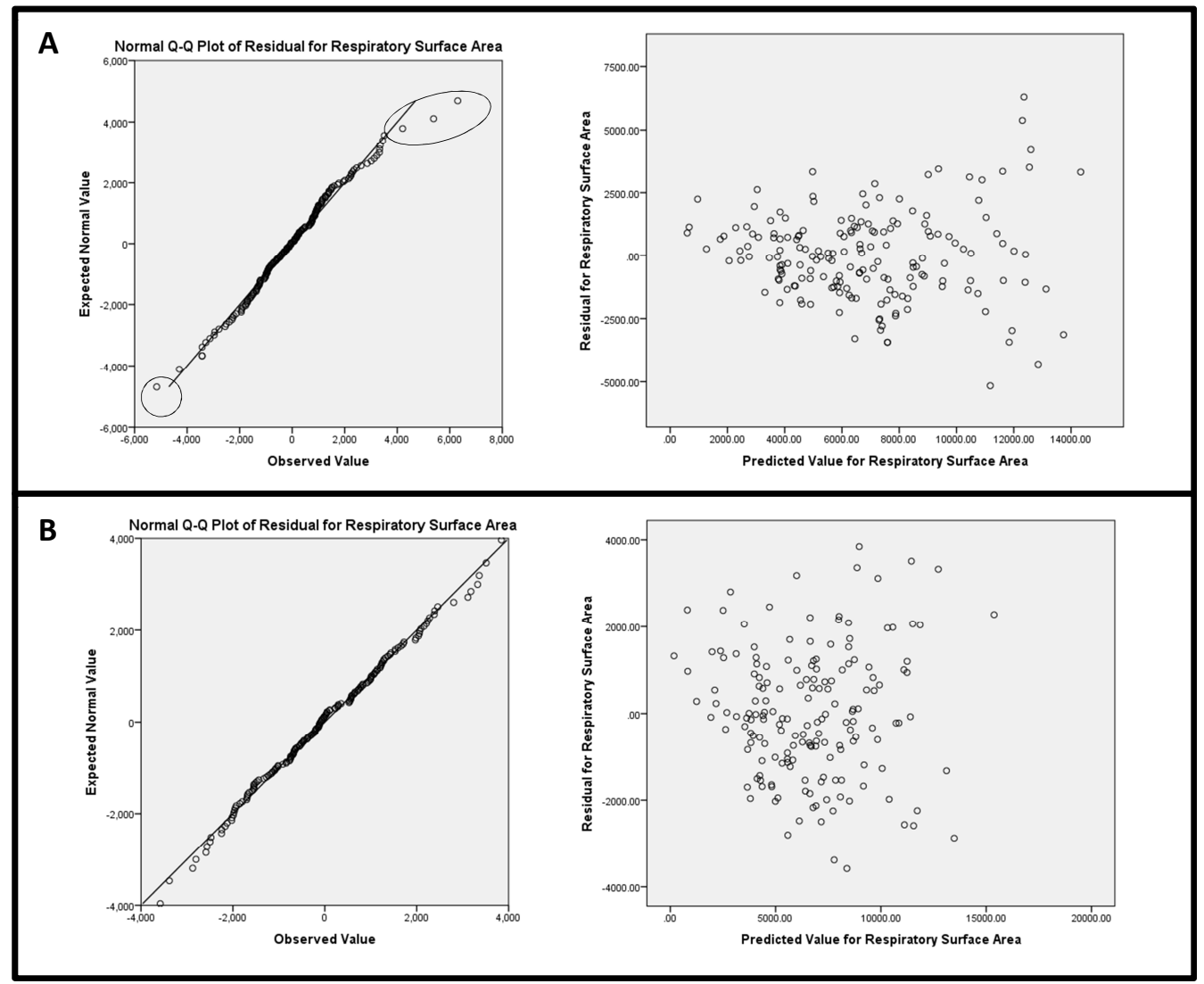

Figure 2. Comparison of $Q-Q$ plots and residuals verses predicted values for respiratory surface area with (A) and without (B) outliers. Outliers are circled.

\section{Results}

\section{Initial visual analysis}

Gambusia affinis had the ability to alter respiratory surface area in response to temperature by increasing or decreasing the size of the interlamellar cell mass. The first changes in gill morphology were seen at six hours; however, significant differences were not seen until twelve hours. Changes in the interlamellar cell mass were similar to those of Gymnocypris prezewalskii (Matey et al., 2008, 2011). Except for a few extreme cases, the interlamellar cell mass did not fully fill the interlamellar spaces. Viewing gills from 
the highest and lowest temperature treatments, using light microscopy, the interlamellar cell masses were significantly shorter for gills in the $26^{\circ} \mathrm{C}$ treatment (Figure $3 \mathrm{~A}$ ) than for gills in the $8^{\circ} \mathrm{C}$ treatment (Figure $3 \mathrm{~B}$ ). These differences were most visible in individuals sampled in the later time points (after $24 \mathrm{hr}$ ).

Likewise, visual differences were found between the highest and lowest temperature treatments. Visual differences are less clear when viewed with SEM. However, in general lamellae were more clearly defined for gills from the $26^{\circ} \mathrm{C}$ treatment (Figure $4 \mathrm{~A}$ ) than for gills in the $8^{\circ} \mathrm{C}$ treatment (Figure $4 \mathrm{~B}$ ). Also, the filament (which includes the interlamellar cell mass) is visibly thicker for the images from the $8^{\circ} \mathrm{C}$ treatment (Figure 4 B). These differences were most visible in individuals sampled in the later time points (after $24 \mathrm{hr}$ ).

There were extreme individuals from the $8^{\circ} \mathrm{C}$ treatment viewed by both light microscopy and SEM. In these individuals, the interlamellar cell mass almost completely or completely filled the interlamellar spaces (Figure 5 A \& B). In these individuals, protruding lamellae could not be seen using SEM (Figure 5 B). This extreme gill remodeling was seen in smaller or average-sized individuals. It was not seen in the larger individuals. This supports the initial observation that there is an effect of size on gill remodeling in G. affinis. 
A

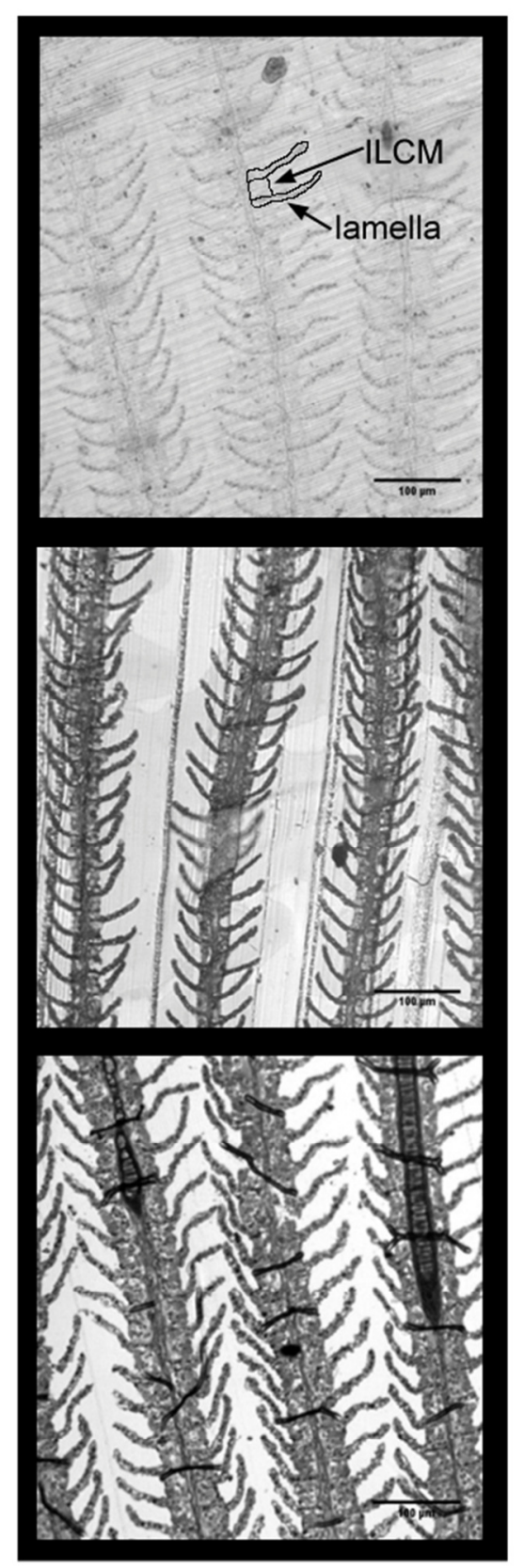

B
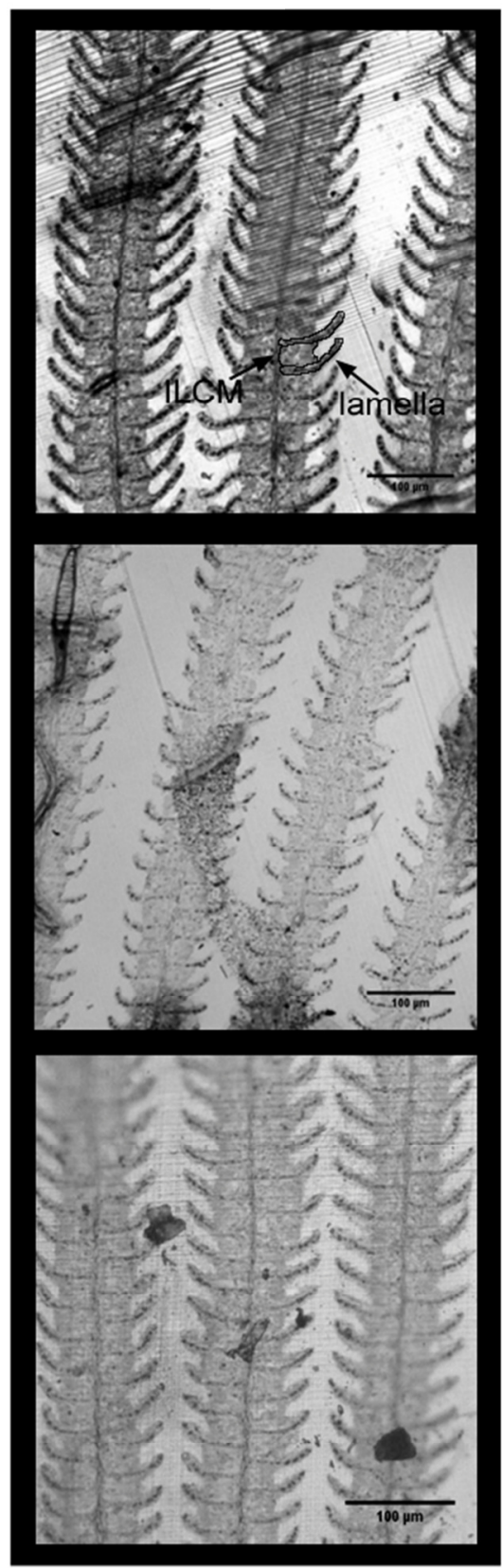

Figure 3. General view of $G$. affinis gill filaments viewed by light microscopy. Gill filaments from three individuals in the $26^{\circ}$ Celcius temperature treatment (A). Gill filaments from three individuals in the $8^{\circ}$ Celcius temperature treatment (B). The interlamellar cell mass (ILCM) is more pronounced for the individuals in the $8^{\circ}$ Celcius temperature treatment. Scale bars represent $100 \mu \mathrm{m}$. 
A

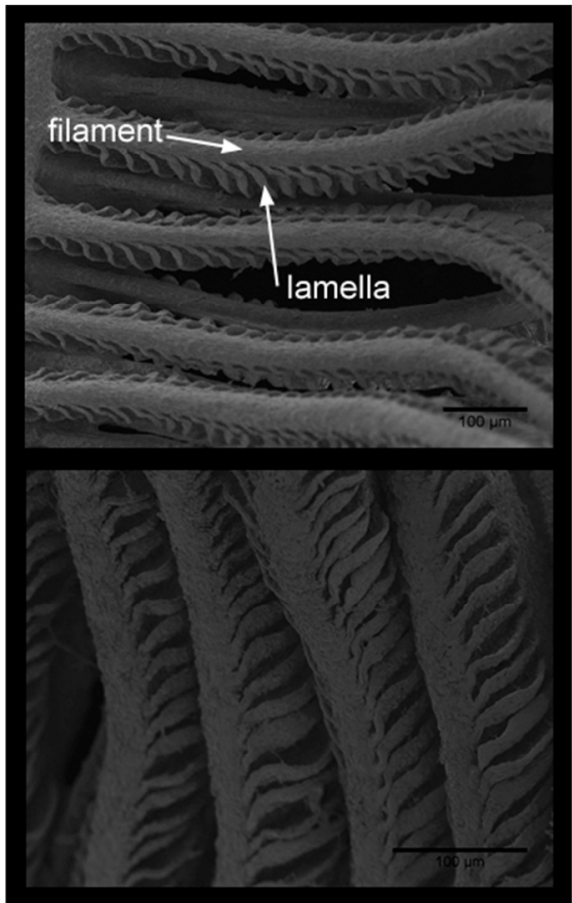

B

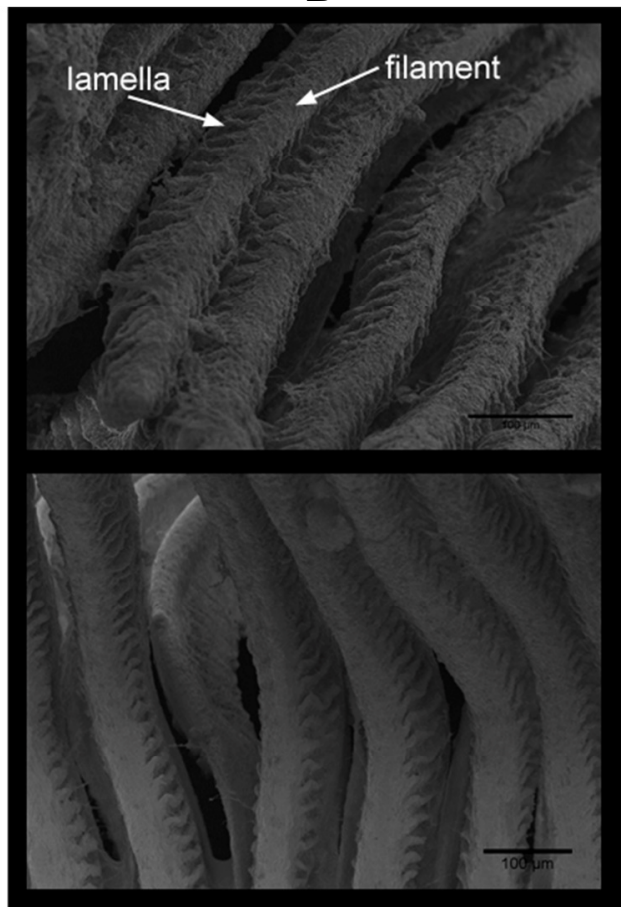

Figure 4. General view of $G$. affinis gill filaments viewed by scanning electron microscopy. Gill filaments from two individuals in the $26^{\circ}$ Celcius temperature treatment (A). Gill filaments from two individuals in the $8^{\circ}$ Celcius temperature treatment (B). Lamellae are more pronounced for individuals in the $26^{\circ}$ Celcius temperature treatment. Scale bars represent $100 \mu \mathrm{m}$.
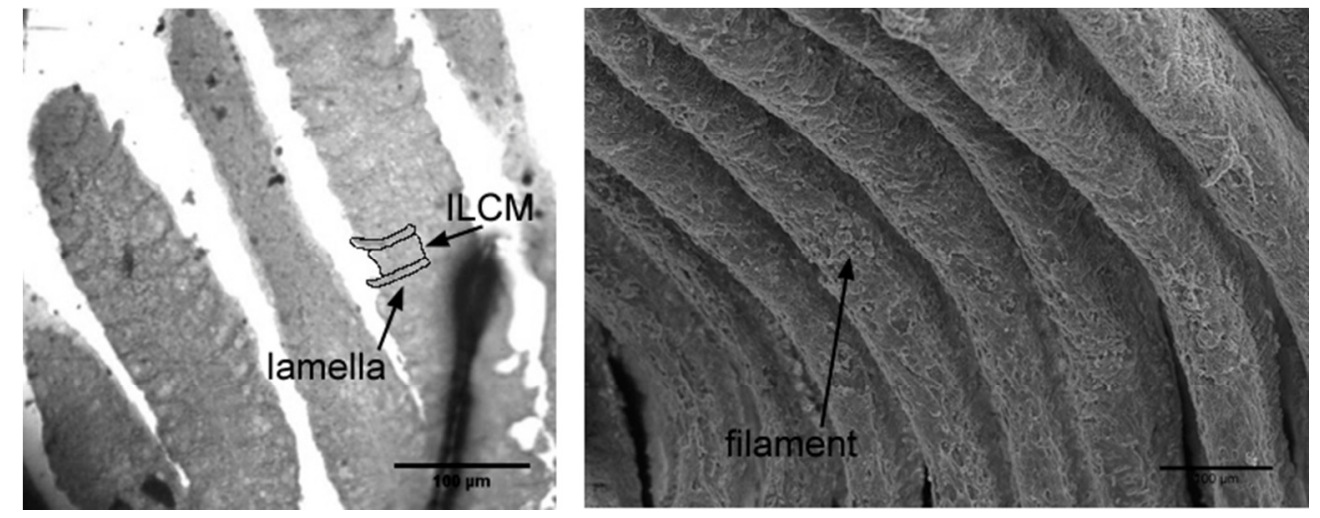

Figure 5. General view of G. affinis gill filaments from a single individual in the $8^{\circ}$ Celcius temperature treatment. Gill filaments viewed by light microscopy (A). Gill filaments viewed by scanning electron microscopy (B). The gill filaments have no protruding lamellae. Scale bars represent $100 \mu \mathrm{m}$. 


\section{Size effects}

There was a significant effect of size on respiratory surface area (Table 2). Linear regressions of fish length (FL), fish weight (FW), and length of longest filament (LLF) all showed a significant positive predictive relationship with respiratory surface area. Linear regression showed that respiratory surface area increased as fish length $(\mathrm{F}(1,31)=$ $14.485, p=0.001)$, fish weight $(\mathrm{F}(1,31)=13.897, p=0.001)$, and length of longest filament $(\mathrm{F}(1,31)=9.813, p=0.004)$ all increased. The length of the shortest filament (LSF) did not show a significant predictive relationship with respiratory surface area

Table 2

Results of linear regression analysis for relationship between four different fish size measurements and respiratory surface area.

\begin{tabular}{|c|c|c|c|c|}
\hline $\begin{array}{c}\text { Fish Size } \\
\text { Measurement }\end{array}$ & $\mathbf{F ( 1 , 3 1 )}$ & $\boldsymbol{p}$ & $\mathbf{R}$ & $\mathbf{R}^{\mathbf{2}}$ \\
\hline FL & 14.485 & .001 & .564 & .318 \\
\hline FW & 13.897 & .001 & .556 & .310 \\
\hline LLF & 9.813 & .004 & .490 & .240 \\
\hline LSF & 3.413 & .074 & .315 & .099 \\
\hline $\begin{array}{c}\text { Fish Size } \\
\text { Component }\end{array}$ & 14.518 & .001 & .565 & .319 \\
\hline
\end{tabular}

Once it was determined that there was an effect of size on respiratory surface area, one size measurement was needed to adjust for this affect in the main temperature and salinity analyses. Principal components analysis (PCA) was used to compare fish length, fish weight and the length of the longest filament to determine if they could be reduced to one size component. Fish length, fish weight and length of the longest filament were all highly correlated (FL-FW, 0.888; FL-LLF, 0.872; FW-LLF, 0.812). Because these measures were highly correlated, it was appropriate to use PCA to reduce 
the correlated size measurements into a single fish size component. One component was extracted, using an eigenvalue-one criterion, which accounted for $90.5 \%$ of the size variance. This fish size component was then used as a covariate and was highly significant in further analyses.

\section{Temperature}

Respiratory surface area. There were significant differences in mean respiratory surface area over time and between temperatures. There was a spike in the respiratory surface area in the $26^{\circ} \mathrm{C}$ treatment at $24 \mathrm{hr}$ and differences in respiratory surface areas between the highest and lowest temperature treatments at later time points. There was a statistically significant interaction between the temperature treatment and time on respiratory surface area, $F(20,137)=1.993, p=0.011$, partial $\eta 2=0.225$. Simple main effects of temperature treatment on time showed that for the $26^{\circ} \mathrm{C}$ treatment there was a statistically significant difference $(F(5,137)=3.933, p=0.002)$ between the mean respiratory surface area at one hour and $24 \mathrm{hr}(p=0.002)$ and at $6 \mathrm{hr}$ and $24 \mathrm{hr}(p=$ 0.002). The mean respiratory surface area for the $26^{\circ} \mathrm{C}$ treatment was significantly higher at $24 \mathrm{hr}\left(10,140.71 \mu \mathrm{m}^{2}, S E M: 819.2 \mu \mathrm{m}^{2}\right)$ than at one hour $\left(5,667.73 \mu \mathrm{m}^{2}, S E M\right.$ : $\left.774.5 \mu \mathrm{m}^{2}\right)$ or at $6 \mathrm{hr}\left(6319.34 \mu \mathrm{m}^{2}, S E M: 801.4 \mu \mathrm{m}^{2}\right)$. Essentially, there was a spike in the respiratory surface area in the $26^{\circ} \mathrm{C}$ treatment at $24 \mathrm{hr}$.

Simple main effects of time on temperature treatment showed several significant differences (Table 3). At $24 \mathrm{hr}(F(4,137)=8.282, p<0.0005)$, the mean respiratory surface area for the $26^{\circ} \mathrm{C}$ treatment was significantly higher than that of the $8^{\circ}(p<$ $0.0005), 12^{\circ}(p=0.035), 17^{\circ}(p<0.0005)$, or the $20^{\circ}(p<0.0005)$ Celsius treatments. At 
$72 \mathrm{hr}(F(4,137)=6.174, p<0.0005)$, the mean respiratory surface area for the $8^{\circ} \mathrm{C}$ treatment was significantly smaller than for the $17^{\circ}(p=0.028), 20^{\circ}(p=0.001)$, or the $26^{\circ}(p<0.0005)$ Celsius treatments. At $120 \mathrm{hr}(F(4,137)=2.794, p=0.029)$, the mean respiratory surface area for the $8^{\circ} \mathrm{C}$ treatment was significantly smaller than for the $26^{\circ} \mathrm{C}$ treatment $(p=0.022)$.

Table 3

Summary of the significance of simple main effects of time and temperature on respiratory surface area.

\begin{tabular}{|c|c|c|c|c|}
\hline $\begin{array}{l}\text { Time } \\
\text { (hrs) }\end{array}$ & $\begin{array}{c}\text { Temperature } \\
\text { Treatment }\end{array}$ & $\begin{array}{l}\text { Mean } \\
\left(\mu \mathrm{m}^{2}\right)\end{array}$ & $\begin{array}{c}\text { Standard } \\
\text { Deviation }\left(\mu \mathrm{m}^{2}\right)\end{array}$ & $p$ \\
\hline \multirow{5}{*}{24} & $26^{\circ} \mathrm{C}$ & $10,140.71$ & 819.2 & \\
\hline & $8^{\circ} \mathrm{C}$ & $4,774.68$ & 756.8 & $<0.0005$ \\
\hline & $12^{\circ} \mathrm{C}$ & $6,912.03$ & 766.4 & 0.035 \\
\hline & $17^{\circ} \mathrm{C}$ & $4,848.99$ & 793.6 & $<0.0005$ \\
\hline & $20^{\circ} \mathrm{C}$ & $5,476.68$ & 753.4 & $<0.0005$ \\
\hline \multirow{4}{*}{72} & $8^{\circ} \mathrm{C}$ & $2,968.51$ & 781.1 & \\
\hline & $17^{\circ} \mathrm{C}$ & $6,125.09$ & 756.7 & 0.028 \\
\hline & $20^{\circ} \mathrm{C}$ & $7,222.01$ & 765.4 & 0.001 \\
\hline & $26^{\circ} \mathrm{C}$ & $7,580.23$ & $\overline{784.2}$ & $<0.0005$ \\
\hline \multirow{2}{*}{120} & $8^{\circ} \mathrm{C}$ & $3,891.37$ & 830.4 & \multirow{2}{*}{0.029} \\
\hline & $26^{\circ} \mathrm{C}$ & $7,318.13$ & 781.3 & \\
\hline
\end{tabular}

There were no significant differences in the respiratory surface area until $24 \mathrm{hr}$. The differences in means at $24 \mathrm{hr}$ showed (as the simple main effects of temperature treatment on time did) a spike in respiratory surface area in the $26^{\circ} \mathrm{C}$ treatment at $24 \mathrm{hr}$. The differences in mean respiratory surface areas at $72 \mathrm{hr}$ and $120 \mathrm{hr}$ both showed 
differences between the lowest temperature treatment and the other temperature treatments. As displayed in Figure 6, the $8^{\circ} \mathrm{C}$ treatment generally decreased over time (indicating a build-up of the interlamellar cell mass) and the $26^{\circ} \mathrm{C}$ treatment generally increased over time (indicating a reduction in the interlamellar cell mass). The respiratory surface area seems to change mainly in the extreme temperatures and vary around a middle value in the moderate temperatures.

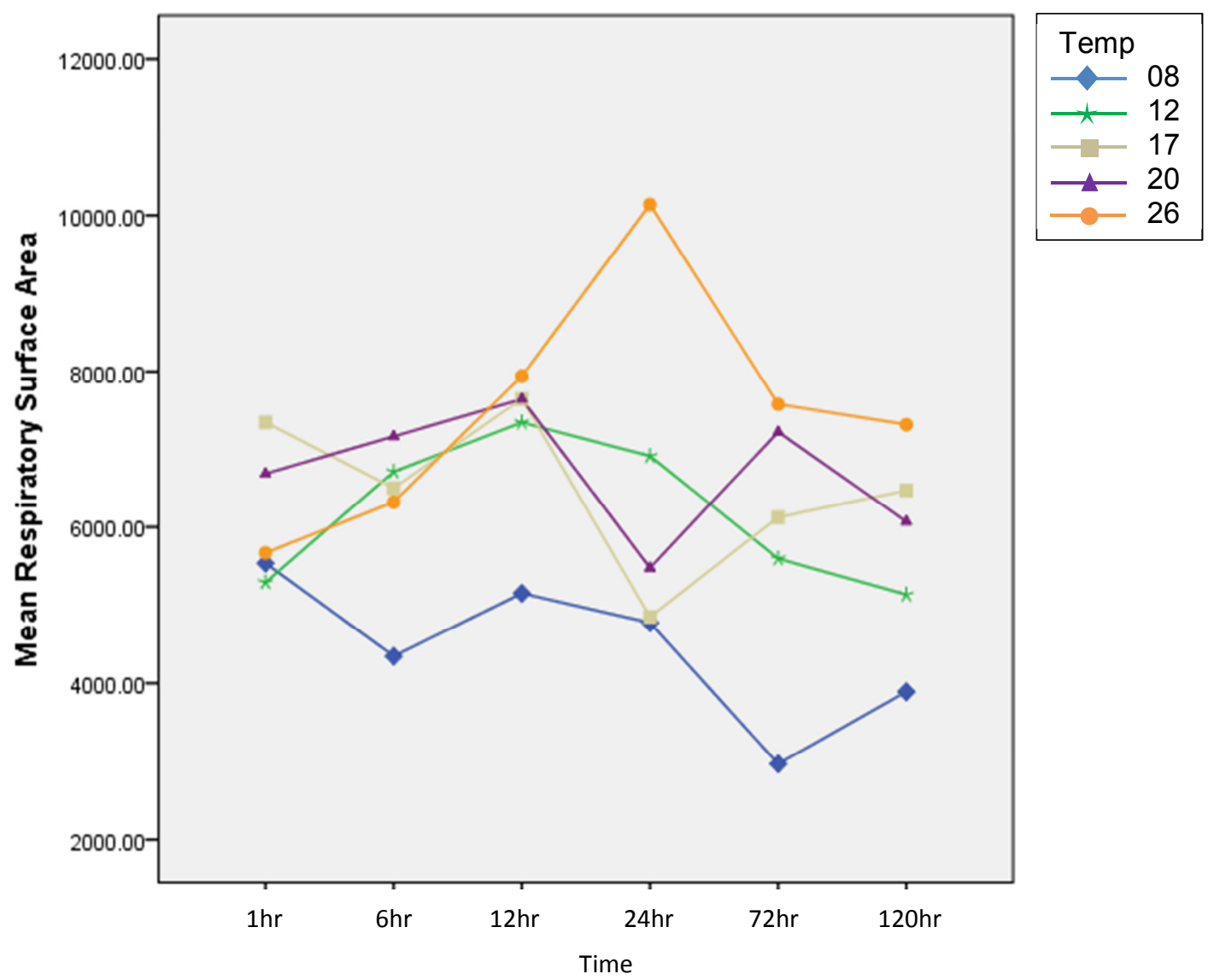

Figure 6. Mean respiratory surface area over time for each temperature treatment.

Protruding lamellar height. There was a statistically significant interaction between the temperature treatment and time on mean protruding lamellar height (PLH), 
$F(20,137)=2.078, p=0.007$, partial $\eta 2=0.233$. Simple main effects of temperature treatment on time showed that for the $12^{\circ} \mathrm{C}$ treatment, the mean protruding lamellar height was significantly longer at $12 \mathrm{hr}(43.84 \mu \mathrm{m}, S E M: 3.4 \mu \mathrm{m})$ than at $120 \mathrm{hr}(24.96$ $\mu \mathrm{m}$, SEM: $3.5 \mu \mathrm{m}, F(5,137)=3.724, p=0.003)$.

Simple main effects of time on temperature treatment showed significant differences in mean protruding lamellar height at $12 \mathrm{hr}(F(4,137)=6.144, p<0.005), 24$ $\operatorname{hr}(F(4,137)=4.747, p=0.001), 72 \mathrm{hr}(F(4,137)=8.128, p<0.005)$, and $120 \mathrm{hr}$ $(F(4,137)=4.690, p=0.001)($ Table 4$)$. At $12 \mathrm{hr}$, mean protruding lamellar height was shorter for the $8^{\circ} \mathrm{C}$ treatment than for the $12^{\circ} \mathrm{C}(p=0.002), 17^{\circ} \mathrm{C}(p=0.037), 20^{\circ} \mathrm{C}(p=$ $0.015)$, or the $26^{\circ} \mathrm{C}(p<0.005)$ treatment. At $24 \mathrm{hr}$, mean protruding lamellar height was longer for the $26^{\circ} \mathrm{C}$ treatment than for the $8^{\circ} \mathrm{C}(p=0.002), 12^{\circ} \mathrm{C}(p=0.042)$, or the $17^{\circ} \mathrm{C}$ ( $p=0.002$ ) treatment. At $72 \mathrm{hr}$, mean protruding lamellar height was shorter for the $8^{\circ} \mathrm{C}$ treatment than for the $20^{\circ} \mathrm{C}(p=0.001)$ and the $26^{\circ} \mathrm{C}(p<0.005)$ treatments. Also at 72 $\mathrm{hr}$, mean protruding lamellar height was shorter for the $17^{\circ} \mathrm{C}$ treatment than for the $26^{\circ} \mathrm{C}$ treatment $(p=0.015)$. Finally, at $120 \mathrm{hr}$, mean protruding lamellar height was longer for the $26^{\circ} \mathrm{C}$ treatment than for the $8^{\circ} \mathrm{C}(p=0.007)$, or the $12^{\circ} \mathrm{C}(p=0.011)$ treatment. 
Table 4

Summary of significance of simple main effects of time and temperature on protruding lamellar height.

\begin{tabular}{|c|c|c|c|c|}
\hline $\begin{array}{l}\text { Time } \\
\text { (hrs) }\end{array}$ & $\begin{array}{c}\text { Temperature } \\
\text { Treatment }\end{array}$ & $\begin{array}{c}\text { Mean } \\
(\mu \mathrm{m})\end{array}$ & $\begin{array}{c}\text { Standard } \\
\text { Deviation }(\mu \mathrm{m})\end{array}$ & $p$ \\
\hline \multirow{5}{*}{12} & $8^{\circ} \mathrm{C}$ & 26.75 & 3.2 & \\
\hline & $12^{\circ} \mathrm{C}$ & 43.84 & 3.4 & 0.002 \\
\hline & $17^{\circ} \mathrm{C}$ & 39.97 & 3.4 & 0.037 \\
\hline & $20^{\circ} \mathrm{C}$ & 41.20 & 3.4 & 0.015 \\
\hline & $26^{\circ} \mathrm{C}$ & 47.38 & 3.4 & $<0.005$ \\
\hline \multirow{4}{*}{24} & $26^{\circ} \mathrm{C}$ & 46.01 & 3.5 & \\
\hline & $8^{\circ} \mathrm{C}$ & 28.16 & 3.3 & 0.002 \\
\hline & $12^{\circ} \mathrm{C}$ & 32.36 & 3.3 & 0.042 \\
\hline & $17^{\circ} \mathrm{C}$ & 28.03 & 3.4 & 0.002 \\
\hline \multirow{5}{*}{72} & $8^{\circ} \mathrm{C}$ & 20.58 & 3.4 & \\
\hline & $20^{\circ} \mathrm{C}$ & 39.18 & 3.3 & 0.001 \\
\hline & $26^{\circ} \mathrm{C}$ & 43.56 & 3.4 & $<0.005$ \\
\hline & \multirow{2}{*}{$\begin{array}{l}17^{\circ} \mathrm{C} \\
26^{\circ} \mathrm{C}\end{array}$} & 39.97 & 3.4 & \multirow{2}{*}{0.015} \\
\hline & & 43.56 & 3.4 & \\
\hline \multirow{3}{*}{120} & $26^{\circ} \mathrm{C}$ & 40.60 & 3.4 & \\
\hline & $8^{\circ} \mathrm{C}$ & 24.14 & 3.6 & 0.007 \\
\hline & $12^{\circ} \mathrm{C}$ & 24.96 & 3.5 & 0.11 \\
\hline
\end{tabular}

The first significant differences in mean protruding lamellar height were seen at $12 \mathrm{hr}$

(Figure 7). The simple main effects of temperature on time, and time on temperature both showed differences in mean protruding lamellar height at $12 \mathrm{hr}$. There was a decrease in mean protruding lamellar height for individuals within the $8^{\circ} \mathrm{C}$ temperature 
treatment between one and six hours. However, this drop was not statistically significantly different until $12 \mathrm{hr}$, when there is an increase in mean protruding lamellar height in the other temperature treatments. After $12 \mathrm{hr}$, the differences in mean protruding lamellar height in the highest $\left(26^{\circ} \mathrm{C}\right)$ and lowest $\left(8^{\circ} \mathrm{C}\right)$ temperature treatments were consistently significant. The other temperature treatments that had significantly different mean protruding lamellar heights from the lowest or highest temperature treatments varied. The mean protruding lamellar height in the $8^{\circ} \mathrm{C}$ treatment decreased and stayed consistently shorter than the other temperature treatments. The mean protruding lamellar height in the $26^{\circ} \mathrm{C}$ treatment increased and stayed consistently longer than the other temperature treatments. The mean protruding lamellar height within the $17^{\circ}$ and $20^{\circ} \mathrm{C}$ treatments varied up and down. The mean protruding lamellar height within the $12^{\circ} \mathrm{C}$ treatment had an unexpected spike at $12 \mathrm{hr}$ and then decreased. 


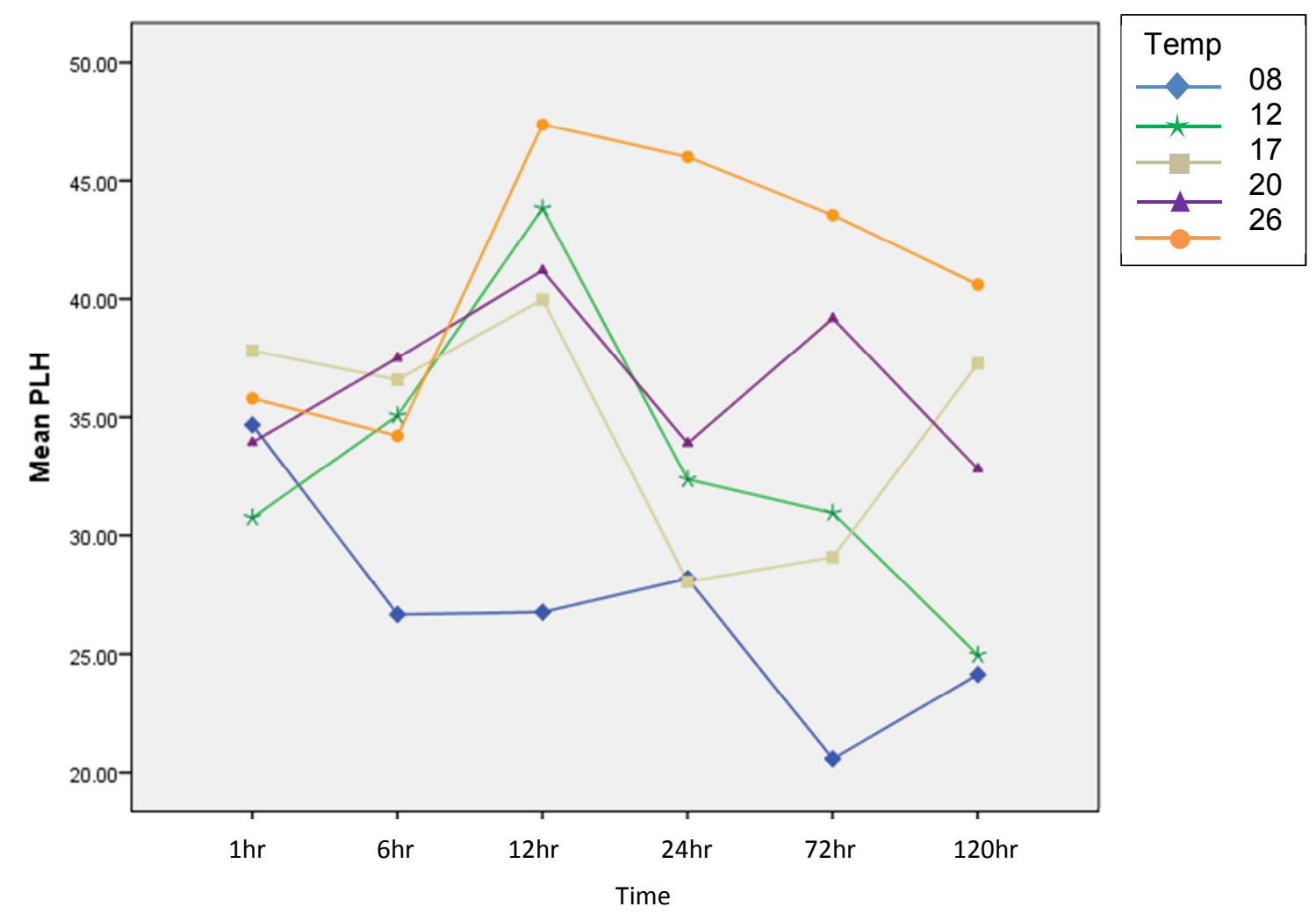

Figure 7. Mean protruding lamellar height (PLH) over time for each temperature treatment.

Protruding lamellar basal length. There was a statistically significant interaction between temperature treatment and time on mean protruding lamellar basal length, $F(20,137)=3.365, p<0.0005$, partial $\eta 2=0.329$. Simple main effects of temperature treatment on time showed significant differences in mean protruding lamellar basal length (PLBL) between times for four temperature treatments: $8^{\circ} \mathrm{C}(F(5,137)=2.783, p$ $=0.020), 12^{\circ} \mathrm{C}(F(5,137)=3.661, p=0.004), 17^{\circ} \mathrm{C}(F(5,137)=3.228, p=0.009)$, and $26^{\circ} \mathrm{C}(F(5,137)=3.094, p=0.011)$. For the $8^{\circ} \mathrm{C}$ treatment, the mean PLBL was significantly longer at $12 \mathrm{hr}(86.63 \mu \mathrm{m}, S E M: 4.6 \mu \mathrm{m})$ than at $120 \mathrm{hr}(64.15 \mu \mathrm{m}, S E M$ : 
$5.1 \mu \mathrm{m}, p=0.015$ ). For the $12^{\circ} \mathrm{C}$ treatment, the mean PLBL was significantly shorter at $12 \mathrm{hr}(65.82 \mu \mathrm{m}, S E M: 4.8 \mu \mathrm{m})$ than at $24 \mathrm{hr}(89.55 \mu \mathrm{m}, S E M: 4.7 \mu \mathrm{m}, p=0.004)$. For the $17^{\circ} \mathrm{C}$ treatment, the mean PLBL was significantly longer at $72 \mathrm{hr}(91.60 \mu \mathrm{m}, S E M$ : $4.6 \mu \mathrm{m})$ than at $6 \mathrm{hr}(70.99 \mu \mathrm{m}, S E M: 4.7 \mu \mathrm{m}, p=0.021)$ or $24 \mathrm{hr}(69.89 \mu \mathrm{m}, S E M: 4.9$ $\mu \mathrm{m}, p=0.012$ ). Finally, for the $26^{\circ} \mathrm{C}$ treatment, the mean PLBL was significantly longer at $24 \mathrm{hr}(87.14 \mu \mathrm{m}, S E M: 5.0 \mu \mathrm{m})$ than at 1 hour $(65.09 \mu \mathrm{m}$, SEM: $4.8 \mu \mathrm{m}, p=0.019)$.

Simple main effects of time on temperature treatment also showed several significant differences at $12 \mathrm{hr}(F(4,137)=3.507, p=0.009), 24 \mathrm{hr}(F(4,137)=4.839, p$ $=0.001)$, and $72 \mathrm{hr}(F(4,137)=3.451, p=0.010)$. At $12 \mathrm{hr}$, mean PLBL for the $8^{\circ} \mathrm{C}$ treatment $(86.63 \mu \mathrm{m}$, SEM: $4.6 \mu \mathrm{m})$ was longer than for the $12^{\circ} \mathrm{C}(65.82 \mu \mathrm{m}$, SEM: 4.8 $\mu \mathrm{m} ; p=0.013)$ or $26^{\circ} \mathrm{C}(67.62 \mu \mathrm{m}, S E M: 4.8 \mu \mathrm{m} ; p=0.033)$ treatments. At $24 \mathrm{hr}$, mean PLBL for the $12^{\circ} \mathrm{C}$ treatment $(89.55 \mu \mathrm{m}, S E M: 4.7 \mu \mathrm{m})$ was longer than for the $17^{\circ} \mathrm{C}$ (69.89 $\mu \mathrm{m}, S E M: 4.9 \mu \mathrm{m} ; p=0.024)$ or $20^{\circ} \mathrm{C}(68.89 \mu \mathrm{m}, S E M: 4.6 \mu \mathrm{m} ; p=0.014)$ treatments. At $72 \mathrm{hr}$, mean PLBL for the $8^{\circ} \mathrm{C}$ treatment $(70.17 \mu \mathrm{m}, S E M: 4.8 \mu \mathrm{m})$ was shorter than for the $17^{\circ} \mathrm{C}(91.60 \mu \mathrm{m}, S E M: 4.6 \mu \mathrm{m} ; p=0.024)$ treatment.

Mean protruding lamellar basal length was highly variable. The results outlined above show large increases or decreases in mean protruding lamellar basal length rather than overall trends (Figure 8). For the $8^{\circ} \mathrm{C}$ treatment, there was a large spike in mean protruding lamellar basal length at $12 \mathrm{hr}$. For the $12^{\circ} \mathrm{C}$ and $26^{\circ} \mathrm{C}$ treatments, there was a large increase in mean protruding lamellar basal length at $24 \mathrm{hr}$. For the $17^{\circ} \mathrm{C}$ treatment, there was a large increase in mean protruding lamellar basal length at $72 \mathrm{hr}$. Overall, the $8^{\circ} \mathrm{C}$ and $20^{\circ} \mathrm{C}$ treatments were the least variable. 


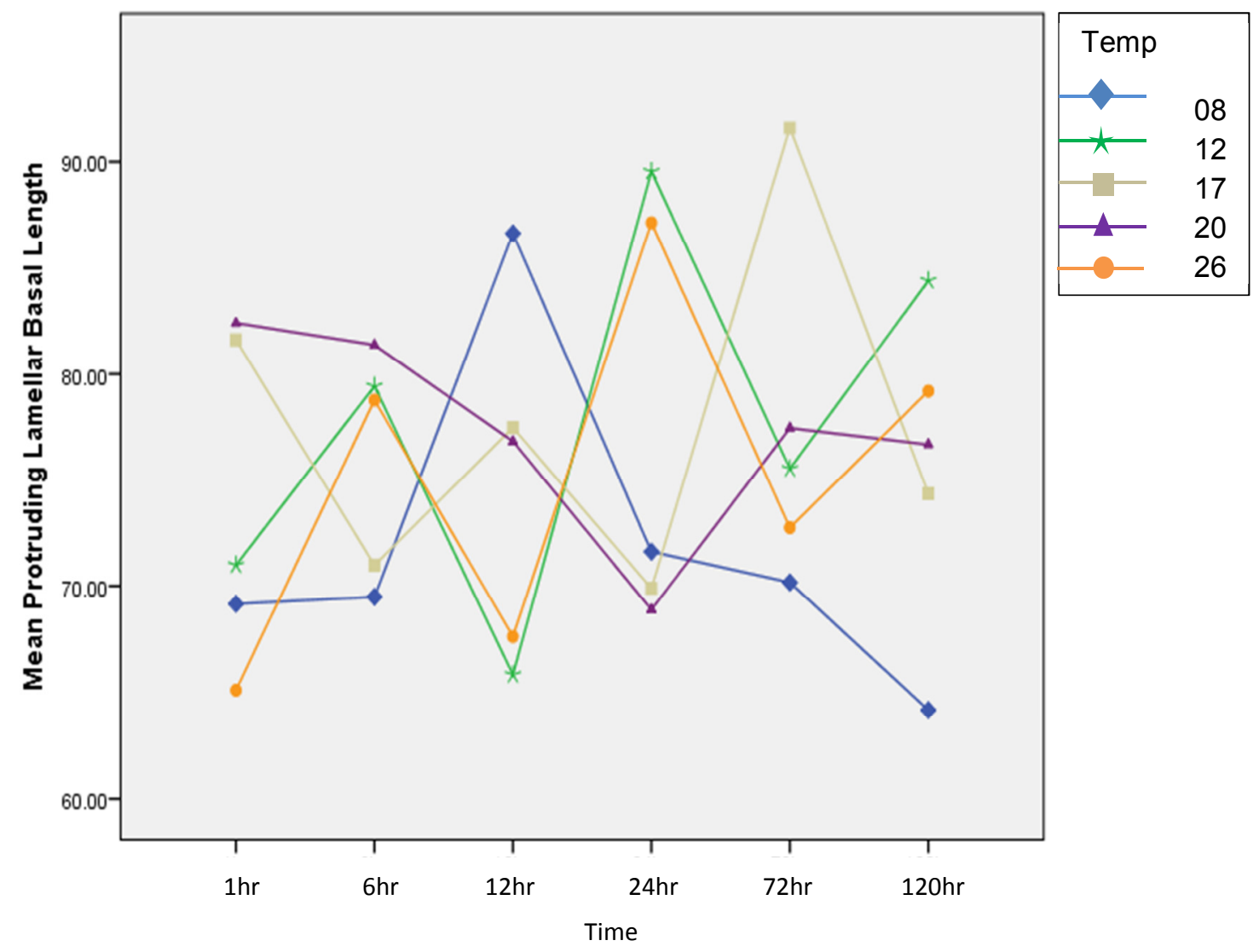

Figure 8. Mean protruding lamellar basal lengths over time for each temperature treatment.

Cross-sectional surface area. There was not a statistically significant interaction between temperature treatment and time on mean cross-sectional surface area, $F(20,137)$ $=0.891, p=0.599$ (Figure 9). Main effects of both time $(F(5,160)=6.611, \mathrm{p}<0.0005)$ and temperature treatment $(F(4,160)=2.649, p=0.035)$ were significant. Bonferroni post-hoc comparisons of temperature treatments showed that the mean cross-sectional surface area for the $8^{\circ} \mathrm{C}$ treatment $\left(707.78 \mu \mathrm{m}^{2}\right)$ was significantly higher than for the $26^{\circ} \mathrm{C}$ treatment $\left(551.23 \mu \mathrm{m}^{2}, p=0.026\right)$. Bonferroni post-hoc comparisons of time showed that the mean cross-sectional surface area at one hour $\left(386.08 \mu \mathrm{m}^{2}\right)$ was 
significantly lower that at $6 \mathrm{hr}\left(584.64 \mu \mathrm{m}^{2}, p=0.003\right), 12 \mathrm{hr}\left(628.01 \mu \mathrm{m}^{2}, p<0.0005\right)$, $24 \mathrm{hr}\left(653.40 \mu \mathrm{m}^{2}, p<0.0005\right)$, or $120 \mathrm{hr}\left(596.683 \mu \mathrm{m}^{2}, p=0.003\right)$.

The mean cross-sectional surface area of the interlamellar cell mass is larger for the $8^{\circ} \mathrm{C}$ treatment than for the other temperature treatments (Figure $9 \mathrm{~A}$ ). In addition, the mean cross-sectional surface area seems to decrease with increasing temperature, although this trend is not statistically significant. Over time, the mean cross-sectional surface area increased until $12 \mathrm{hr}$ and then seemed to level off and decrease slightly (Figure 9 B).
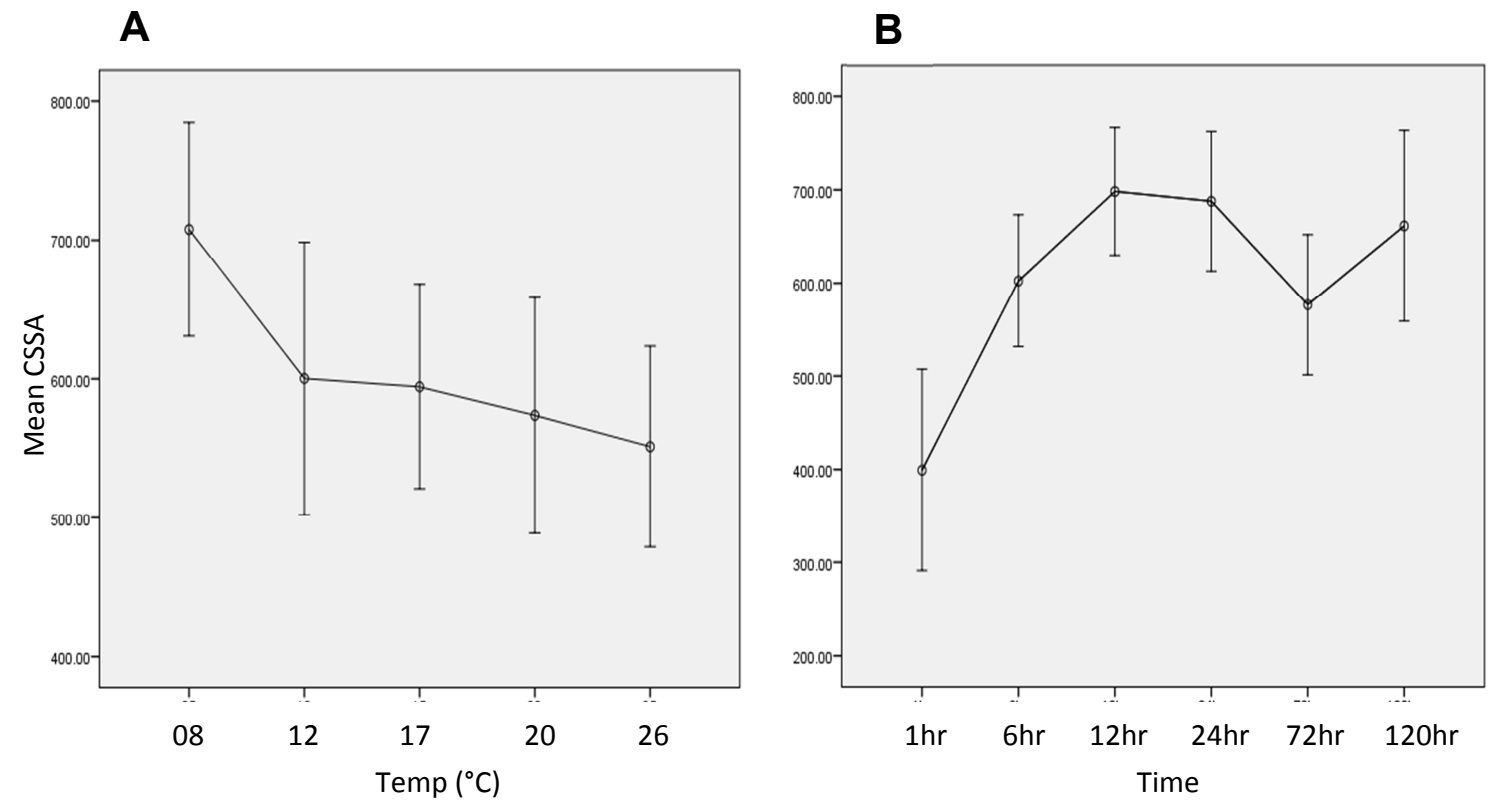

Figure 9. Mean cross-sectional surface area (CSSA) between temperature treatments (A). Mean cross-sectional surface area (CSSA) over time (B). Bars represent standard errors.

Lamellar thickness. There was not a statistically significant interaction between temperature treatment and time on mean lamellar thickness, $F(20,137)=1.034, p=$ 0.428. Main effects of both time $(F(5,157)=1.949, p=0.089)$ and temperature 
treatment $(F(4,157)=2.326, p=0.059)$ were not significant (Figure 10 A \& B). There was high variability in lamellar thickness. Although not statistically significant, there was a tendency to decrease in lamellar thickness for the $8^{\circ} \mathrm{C}$ treatment (Figure $10 \mathrm{~A}$ ) and a switch point at $12 \mathrm{hr}$ similar to other morphometric variables described above (Figure $10 \mathrm{~B})$.
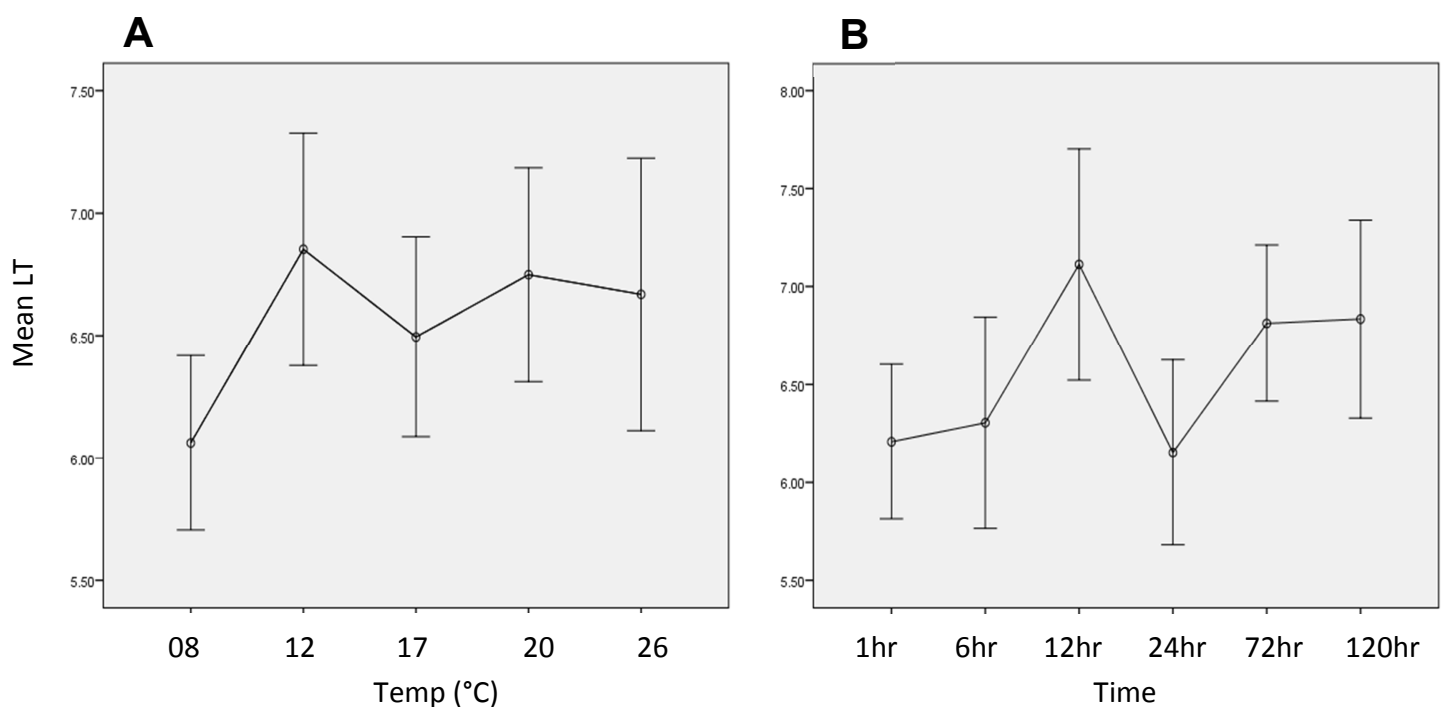

Figure 10. Mean lamellar thickness (LT) between temperature treatments (A). Mean lamellar thickness (LT) over time (B). No significant differences were found. Bars represent standard errors.

Filament thickness. There was a statistically significant interaction between the temperature treatment and time on filament thickness, $F(20,137)=1.664, p=0.047$, partial $\eta 2=0.195$. Simple main effects of temperature treatment on time showed no significant differences. Simple main effects of time on temperature treatment showed significant differences in mean filament thickness at $72 \mathrm{hr}(F(4,137)=4.314, p=0.003)$ and $120 \mathrm{hr}(\mathrm{F}(4,137)=3.480, p=0.010)$. At $72 \mathrm{hr}$, the mean filament thickness for the 
$8^{\circ} \mathrm{C}$ treatment $(30.08 \mu \mathrm{m}, S E M: 2.7 \mu \mathrm{m})$ was significantly thinner than for the $17^{\circ} \mathrm{C}$ treatment $(40.65 \mu \mathrm{m}, S E M: 2.66 \mu \mathrm{m}, p=0.044)$. At $120 \mathrm{hr}$, the mean filament thickness for the $8^{\circ} \mathrm{C}$ treatment $(27.03 \mu \mathrm{m}, S E M: 2.92 \mu \mathrm{m})$ was significantly thinner than for the $12^{\circ} \mathrm{C}$ treatment (41.02 $\mu \mathrm{m}$, SEM: $\left.2.82 \mu \mathrm{m}, p=0.007\right)$.

Mean filament thickness was significantly thinner for the $8^{\circ} \mathrm{C}$ treatment at the later times (Figure 11). The mean filament thickness for both the $8^{\circ} \mathrm{C}$ and the $26^{\circ} \mathrm{C}$ treatments tended to trend downwards. Thus, a thinning of the water-blood diffusion distance in response to decreased surface area in the $8^{\circ} \mathrm{C}$ treatment and in response to decreased oxygen concentrations in the surrounding water in the $26^{\circ} \mathrm{C}$ treatment had occurred.
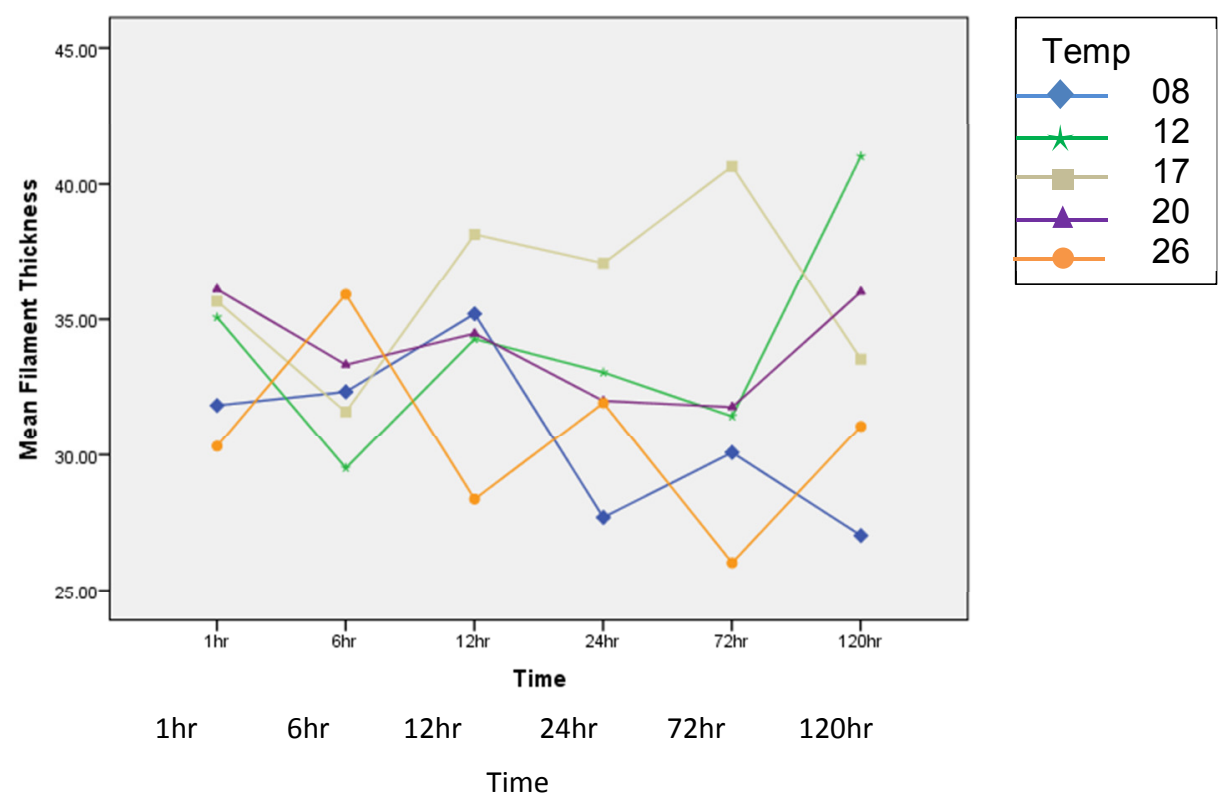

Figure 11. Mean tilament thicknesses over time tor each temperature treatment. 


\section{Salinity}

Respiratory surface area. There was not a statistically significant interaction between the salinity treatment and time on respiratory surface area, $F(17,98)=0.962, p=$ 0.506 (Figure 12). Main effects of both salinity $(F(4,98)=1.591, p=0.183$ ) and time were not significant $(F(4,98)=1.863, p=0.108)$. The mean respiratory surface area over time and between salinity treatments was highly variable and demonstrated no significant trends. The effect of salinity on mean respiratory surface area showed no clear trends (Figure $12 \mathrm{~B}$ ). The effect of time mean respiratory surface area seems to show a peak at $12 \mathrm{hr}$, although this is not statistically significant (Figure $12 \mathrm{~A}$ ).
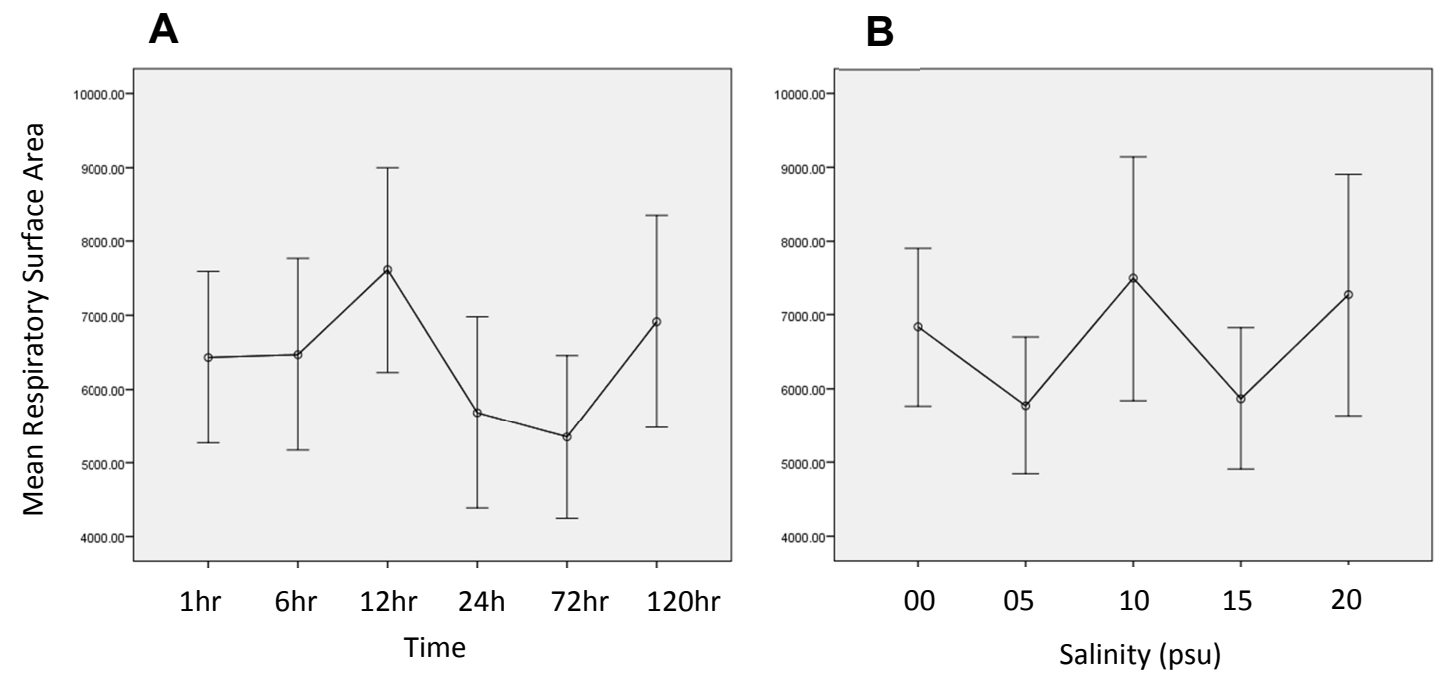

Figure 12. Mean respiratory surface area over time (A). Mean respiratory surface area between salinity treatments (B). No significant differences were present. Bars represent standard errors.

Protruding lamellar height. There was not a statistically significant interaction between salinity treatment and time on protruding lamellar height, $F(17,98)=0.668, p=$ 0.827. Main effects of both salinity $(F(4,98)=0.676, p=0.610)$ and time were not 
significant $(F(4,98)=1.938, p=0.095)$ (Figure $13 \mathrm{~A} \& \mathrm{~B}$ ?). The mean protruding lamellar height over time and between salinity treatments was highly variable, with no significant trends. The effect of salinity on protruding lamellar height showed no clear trends (Figure $13 \mathrm{~B}$ ). The effect of time on protruding lamellar height tended to show a peak at $12 \mathrm{hr}$, although this is not statistically significant (Figure $13 \mathrm{~A}$ ).

A

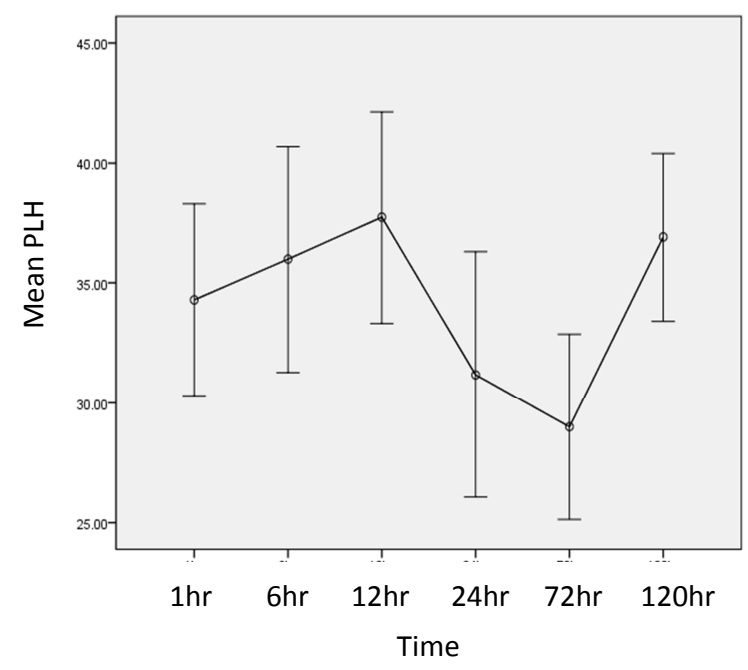

B

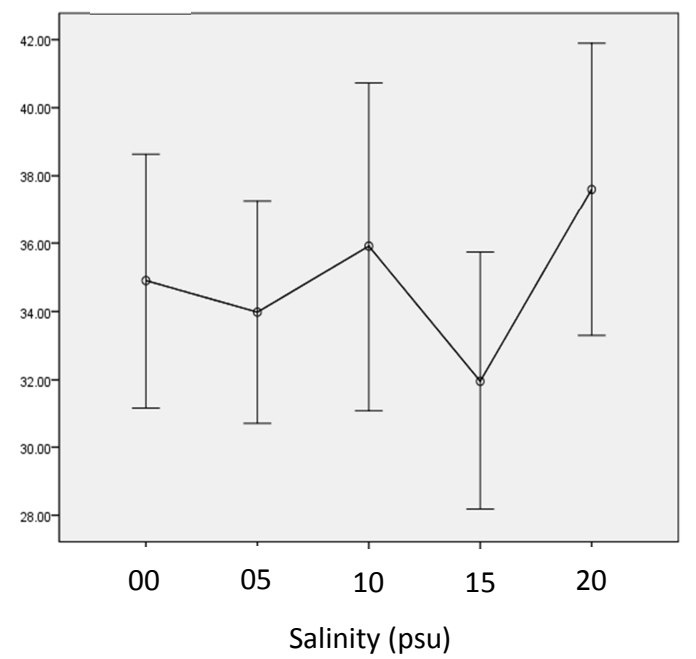

Figure 13. Mean protruding lamellar height (PLH) over time (A). Mean protruding lamellar height between salinity treatments (B). No significant differences were present. Bars represent standard errors.

Protruding lamellar basal length. There was a statistically significant interaction between salinity treatment and time on mean protruding lamellar basal length, $F(17,98)=$ $2.035, p=0.016$, partial $\eta 2=0.259$. Simple main effects of salinity on time showed a significant difference for the 0 psu salinity treatment, $F(5,99)=3.077, p=0.013$. The mean protruding lamellar basal length at $6 \mathrm{hr}(72.29 \mu \mathrm{m}, S E M: 4.6 \mu \mathrm{m})$ was significantly shorter than at $72 \mathrm{hr}(96.28 \mu \mathrm{m}, S E M: 4.6 \mu \mathrm{m}, p=0.006)$. Simple main effects of time 
on salinity showed significant differences at $12 \mathrm{hr}(F(5,99)=2.579, p=0.042), 72 \mathrm{hr}$ $(F(5,99)=4.374, p=0.006)$, and $120 \mathrm{hr}(F(5,99)=2.962, p=0.036)$. At $12 \mathrm{hr}$, the mean protruding lamellar basal length was shorter for the 5 psu salinity treatment $(78.07 \mu \mathrm{m}$, SEM: $4.6 \mu \mathrm{m})$ than for the $10 \mathrm{psu}$ salinity treatment $(102.03 \mu \mathrm{m}, S E M: 6.6 \mu \mathrm{m}, p=$ 0.036). At $72 \mathrm{hr}$, the mean protruding lamellar basal length for the $0 \mathrm{psu}(96.28 \mu \mathrm{m}$, SEM: $4.6 \mu \mathrm{m})$ salinity treatment was significantly longer than for the $5 \mathrm{psu}(76.02 \mu \mathrm{m}$, SEM: $4.7 \mu \mathrm{m}, p=0.016)$ or $15 \mathrm{psu}(76.2 \mu \mathrm{m}, S E M: 4.7 \mu \mathrm{m}, p=0.017)$ salinity treatments. At $120 \mathrm{hr}$, the mean protruding lamellar basal length was shorter for the 5 psu salinity treatment $(68.39 \mu \mathrm{m}, S E M: 4.7 \mu \mathrm{m})$ than for the $10 \mathrm{psu}$ salinity treatment (92.55 $\mu \mathrm{m}$, SEM: $6.6 \mu \mathrm{m}, p=0.022)$.

Similar to mean values for the temperature treatments, the mean protruding lamellar basal length was highly variable (Figure 14). The significant differences in mean protruding lamellar basal length seem to indicate large increases or decreases rather than overall trends. The mean protruding lamellar basal length increased for the 0 psu treatment at $72 \mathrm{hr}$ and for the $10 \mathrm{psu}$ treatment at $12 \mathrm{hr}$. There was also a large increase for the 10 psu treatment while there was a decrease for the 5 psu treatment. 

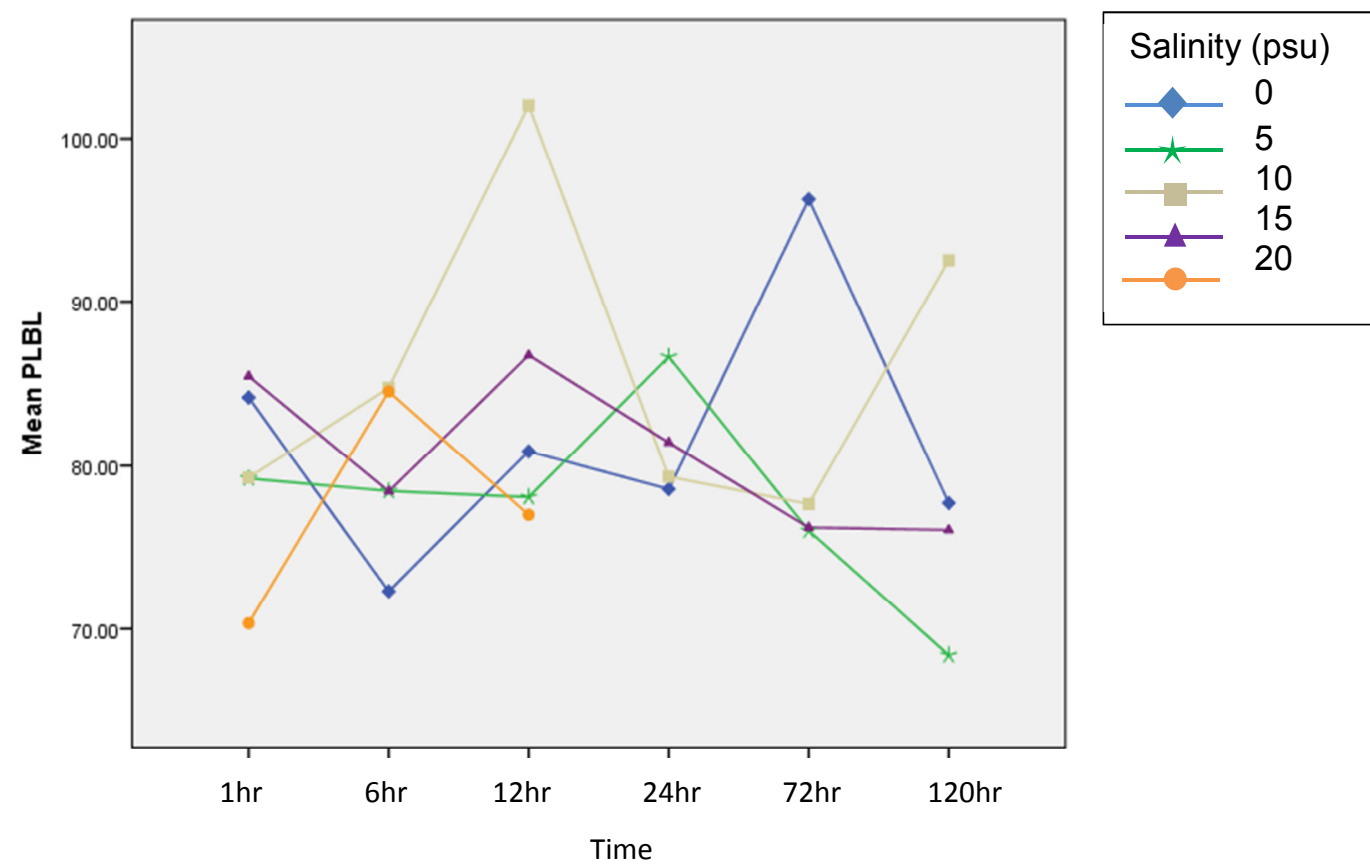

Figure 14. Mean protruding lamellar basal length (PLBL) over time between salinity treatments.

Cross-sectional surface area. There was not a statistically significant interaction between salinity treatment and time on mean cross-sectional surface area, $F(17,98)=$ 0.080, $p=0.080$. Main effect of salinity treatment on mean cross-sectional surface area was not significant $(F(4,99)=2.180, p=0.077)$. Main effect of time on mean crosssectional surface area was significant $(F(5,99)=4.112, p=0.002)$. The mean crosssectional surface area was greater at $24 \mathrm{hr}\left(699.60 \mu \mathrm{m}^{2}, S E M: 45.7 \mu \mathrm{m}^{2}\right)$ than at one hour (495.49 $\mu \mathrm{m}^{2}$, SEM: $\left.42.2 \mu \mathrm{m}^{2}, p=0.021\right)$ or at $72 \mathrm{hr}\left(469.13 \mu \mathrm{m}^{2}, S E M: 44.6 \mu \mathrm{m}^{2}, p=\right.$ $0.021)$.

The mean cross-sectional surface area increased until between $12 \mathrm{hr}$ and $24 \mathrm{hr}$, and then began to decrease (Figure $15 \mathrm{~A}$ ). Although not statistically significant, there 
tended to be a larger mean cross-sectional surface area for the 10 psu treatment and a smaller mean cross-sectional surface area for the 20 psu treatment (Figure $15 \mathrm{~B}$ ).
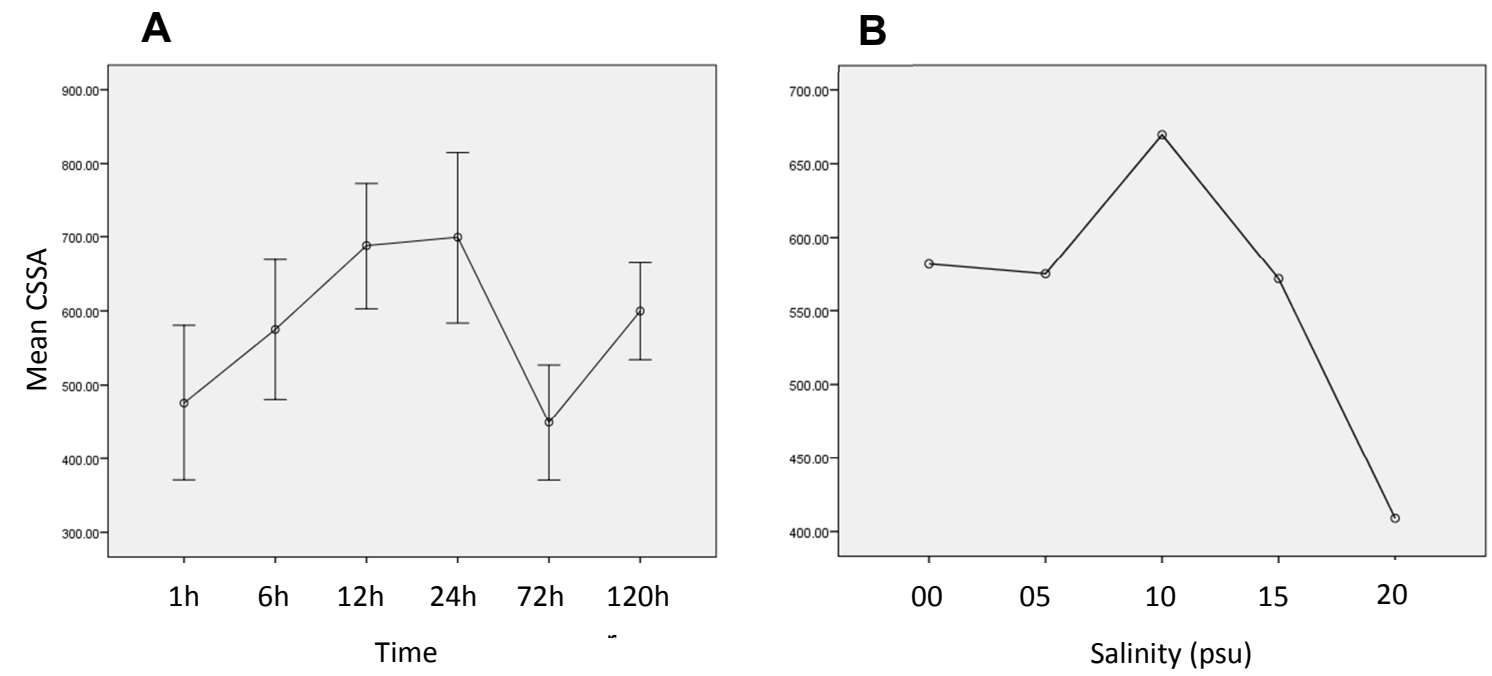

Figure 15. Mean cross-sectional surface area (CSSA) over time (A). Mean crosssectional surface area (CSSA) between salinity treatments (B). No significant differences were present between salinity treatments. Bars represent standard errors.

Lamellar thickness. There was not a statistically significant interaction between salinity treatment and time on mean lamellar thickness, $F(17,99)=1.270, p=0.228$ (Figure 16). Main effect of salinity treatment on mean cross-sectional surface area was significant $(F(4,99)=3.076, p=0.020)$. Lamellar thickness was significantly smaller for the 0 psu salinity treatment $(6.395 \mu \mathrm{m}, S E M: 0.206 \mu \mathrm{m})$ than for the $10 \mathrm{psu}$ salinity treatment (7.470 $\mu \mathrm{m}, S E M: 0.286 \mu \mathrm{m}, p=0.029)$ (Figure 16). Main effect of time on mean cross-sectional surface area was not significant $(F(5,99)=2.251, p=0.055)$. 


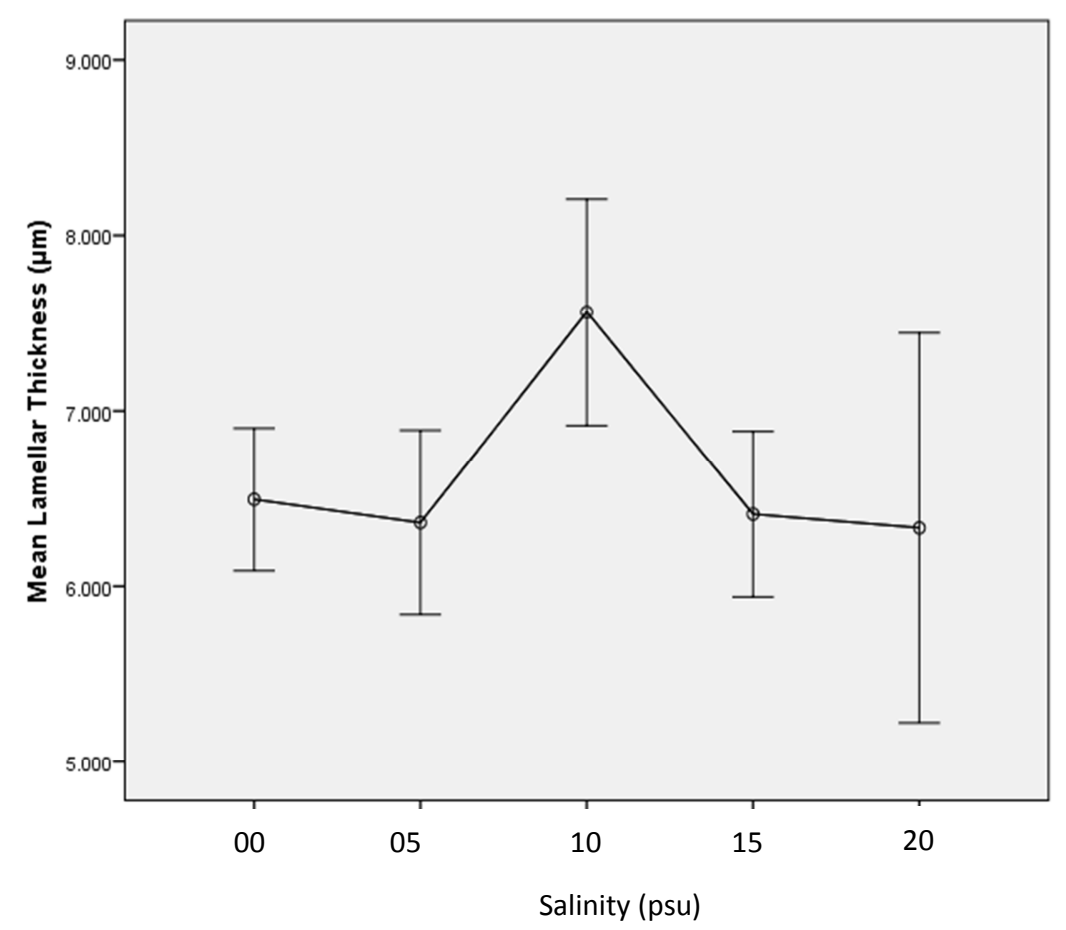

Figure 16. Mean lamellar thicknesses between salınıty treatments. Bars represent standard errors.

Filament thickness. There was not a statistically significant interaction between salinity treatment and time on filament thickness, $F(17,99)=1.416, p=0.145$. Main effect of salinity treatment on filament thickness was not significant $(F(4,99)=2.090, p=$ 0.088). Main effect of time on mean filament thickness was significant $(F(5,99)=3.642$, $p=0.005)$. Mean filament thickness was significantly larger at $120 \mathrm{hr}(11.817 \mu \mathrm{m}, S E M$ : $0.493 \mu \mathrm{m})$ than at one hour $(9.693 \mu \mathrm{m}, S E M: 0.431 \mu \mathrm{m}, p=0.024)$ or $72 \mathrm{hr}(9.381 \mu \mathrm{m}$, SEM: $0.456 \mu \mathrm{m}, p=0.007)$.

There was a large difference in filament thickness at the beginning and the end of the experiment (Figure $17 \mathrm{~A}$ ). There was not a general increase over the course of the experiment, rather a thinner filament thickness at one hour and a wider filament thickness 
at $120 \mathrm{hr}$. Although not statistically significant, there was a trend of decreasing filament thickness with increasing salinity (Figure 17 B).
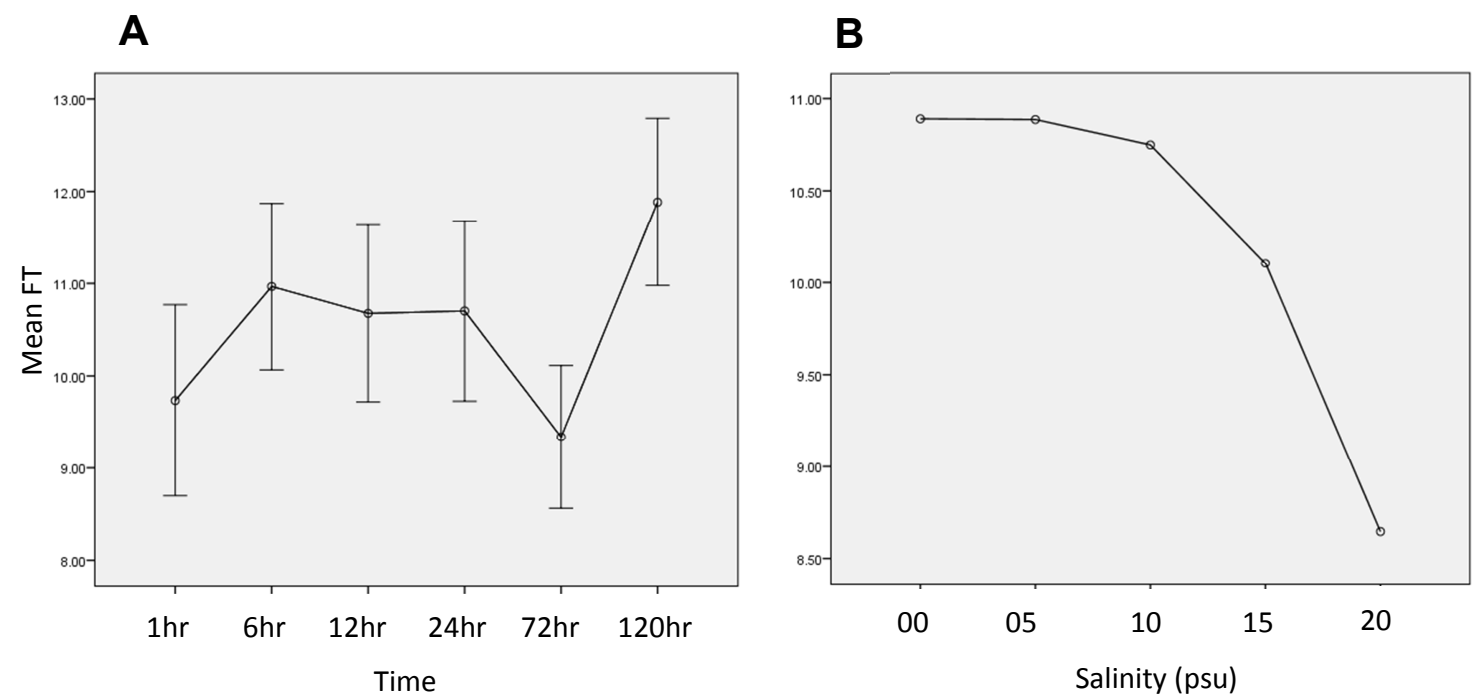

Figure 17. Mean filament thickness (FT) over time (A). Mean filament thickness between salinity treatments (B). No significant differences were present between salinity treatments. Bars represent standard errors.

\section{Discussion}

This study confirms that Gambusia affinis can remodel its gills in response to temperature. There was a visible difference in the interlamellar cell mass between the highest and lowest temperature treatments. This was further supported by the statistically significant differences in respiratory surface area, protruding lamellar height, crosssectional surface area, and filament thickness. The results of several studies (Matey et al., 2008; Rissanen, Tranberg, Sollid, Nilsson, \& Nikinmaa, 2006; Sollid et al., 2003, 2005) indicate that gill remodeling occurs mainly in response to oxygen demands. Gill remodeling occurs as oxygen concentrations and temperatures change drastically. Different temperatures have different dissolved oxygen concentrations and result in 
different metabolic oxygen needs. The results for the temperature treatments in this experiment support this conclusion.

Previous studies found that respiratory surface area, protruding lamellar height and protruding lamellar basal length all increased while lamellar thickness, filament thickness, and ILCM volume (similar measure to cross-sectional surface area) decreased with increased temperature or with hypoxia exposure (Matey et al., 2008; Sollid et al., 2005; Sollid et al., 2005, 2003). Results of this study showed that respiratory surface area and protruding lamellar height increased while filament thickness and crosssectional surface area decreased with increased temperature. Protruding lamellar basal length and lamellar thickness did not significantly differ between temperature treatments. Protruding lamellar basal length should be a direct result of the size of the interlamellar cell mass. As the interlamellar cell mass increases, it covers more of the lamellae. Lamellae curve slightly at the afferent and efferent edges, so that they are wider at the base than at the top edge. As the interlamellar cell mass increases, the protruding lamellar basal length should decrease (Sollid et al., 2003). However, looking at the SEM images of G. affinis lamellae revealed that they tend to curve in more at the ends than at the base. Because the interlamellar cell mass does not completely fill the interlamellar space, changes in protruding lamellar basal length may be less for G. affinis than for those measured in C. carassius or C. auratus.

Changes in protruding lamellar basal length and lamellar thickness were both highly variable. This could have been due to the large range of sizes of fish within this study. Size factors represented by the fish size component were highly significant 
covariates in the analysis of every morphometric variable. This size variability may have reduced the power of the analysis to detect all but the most significant differences in the morphometric variables measured, decreasing the overall power of the analysis. Variability was also affected by the changes of each variable over time. The aim of sampling at different times in this study was to try to capture when the change in the ILCM was complete and if it stayed constant after completion. It is possible that in a more simplistic experimental design comparing similarly-sized individuals, differences in protruding lamellar basal length and lamellar thickness would be statistically significant.

Although the effect of oxygen demand on gill remodeling is well documented, the fish gill is multifunctional organ system. Gill remodeling may be the result of a compromise between competing ionoregulatory and oxygen needs (Evans et al., 2005; McDonald, Freda, Cavdek, Gonzalez, \& Zia, 1991). Because of this compromise, this study aimed to explore changes in salinity as another possible trigger of gill remodeling. It was hypothesized that with increasing salinity there would be increased costs in ionoregulation that would trigger a decrease in respiratory surface area, protruding lamellar height, and protruding lamellar basal length, and that cross-sectional surface area, lamellar thickness and filament thickness would decrease with increasing salinity. However, no significant differences were found in respiratory surface area or protruding lamellar height between salinity treatments.

There were significant differences in protruding lamellar basal lengths between salinity treatments and over time. However, these differences were the result of extreme values rather than an indication of significant gill remodeling. Differences in lamellar 
thickness were also the result of extreme values.

Differences in cross-sectional surface area and filament thickness, however, did seem to be biologically relevant rather than the result of extreme values. Cross-sectional surface area increased, plateaued between $12 \mathrm{hr}$ and $24 \mathrm{hr}$, and then decreased. This coincided with peaks in respiratory surface area, protruding lamellar height, crosssectional surface area, and filament thickness between $12 \mathrm{hr}$ and $24 \mathrm{hr}$ for the temperature treatments. Although it was too variable to be statistically significant, there was a trend of decreasing filament thickness with increasing salinity, as was expected.

As outlined previously, size variability was highly significant within this study. In future studies, this would be more carefully controlled. The variability in size may have affected the power of the analysis to detect differences in the morphometric variables measured. However, fishes have other means of compensating for changing ionoregulatory needs. Fish can change the shape and distribution of mitochondria-rich cells (often called chloride cells) which are important in ion regulation (Hiroi \& McCormick, 2007; Inokuchi, Hiroi, Watanabe, Hwang, \& Kaneko, 2009; Matey et al., 2011). Fish can also change the surface area of micro ridges on the surface of pavement cells or release protective mucus across the gill surface (Matey et al., 2008, 2011). In the same order (Cyprinodontiformes) as G. affinis, Kryptolebias marmoratus can ionoregulate though its skin (LeBlanc et al., 2013). Changes in salinity may trigger small-scale cellular changes rather than a change in the interlamellar cell mass.

Gill remodeling is a surprising adaptation that could be widespread within certain orders of fishes. Documenting the presence of this phenomenon in G. affinis has 
important implications in understanding how fishes adapt to adverse environments. $G$. affinis was chosen as the study species because of its relationship to K. marmoratus and because of its ability to live within a wide range of environmental conditions. G. affinis and K. marmoratus have very different modes of life. The ability to remodel the gills in both of these species indicates a possible widespread presence of gill remodeling within the Cyprinodontiformes.

Because they are not closely related, it is also important to note that the same environmental conditions trigger gill remodeling in cypriniform (Carassius carassius, Carassius auratus, and Gymnocypris prezewalskii) and cyprinodontiform (G. affinis) fishes. G. affinis has the ability to remodel its gills in response to changes in temperature (and the resulting change in oxygen concentrations/oxygen needs) rather than aerial exposure, as seen for K. marmoratus. This suggests possible convergent evolution in the gill remodeling ability in these two distant orders Cyprinidontiformes and Cypriniformes. It is possible that this ability is relatively 'easy' to evolve, or that this ability is strongly selected for in certain environmental conditions. I hypothesize the latter, that this ability has evolved independently within these two orders of fishes due to similar, stressful environmental conditions. As was shown in Part 1 of this thesis, the interlamellar cell mass has important effects on flow and oxygen uptake, however, the presence of the interlamellar cell mass does not seem to negatively affect overall metabolic rate (Sollid et al., 2005; Tzaneva, Bailey, \& Perry, 2011; Tzaneva, Gilmour, et al., 2011). The benefit of increased oxygen uptake in hypoxia or high temperatures and decreased ion loss in normoxic waters offsets the possible negative effects of the presence of the interlamellar 
cell mass and any energy costs in maintaining and decreasing the interlamellar cell mass.

The ability to remodel gills has been observed in only four species of fish in previous literature (Matey et al., 2008; Ong et al., 2007; Sollid et al., 2003; Sollid et al., 2005). This study confirms a fifth species of fish with the ability to remodel gills. The implications of the phylogenetic relationships described above are exciting. The discovery of this ability in these two distant orders, Cyprinidontiformes and Cypriniformes, suggests that this ability is may be present in many other species of fish. Further exploration of this ability in these and other orders of fishes may give important insight into the adaptability of fishes. 


\section{References}

Al-Daham, N. K., \& Bhatti, M. N. (1977). Salinity tolerance of Gambusia afinis ( Baird \& Girard ) and Heteropneustes fossilis ( Bloch ). Journal of Fish Biology, 11, 309313.

Baeuf, G., \& Payan, P. (2001). How should salinity influence fish growth? Comparative Biochemistry and Physiology Part C: Toxicology and Pharmacology, 130, 411-423.

Bozzola, J. J., \& Russell, L. D. (1991). Electron Microscopy: Principles and Techniques for Biologists. Sudbury, MA: Jones and Bartlett Publishers.

Brauner, C. J., Matey, V., Zhang, W., Richards, J. G., Dhillon, R., Cao, Z.-D., .. Fu, S.J. (2008). Gill remodeling in crucian carp during sustained exercise and the effect on subsequent swimming performance. Physiological and Biochemical Zoology : PBZ, 84(6), 535-42. doi:10.1086/662664

Cailliet, G., Love, M., \& Ebling, A. (1996). Fishes: A Feild and Laboratory Manual on Their Structure, Identification and Natural History. Long Grove, IL: Waveland Press.

Chapman, L. J., Galis, F., \& Shinn, J. (2000). Phenotypic plasticity and the possible role of genetic assimilation: Hypoxia-induced trade-offs in the morphological traits of an African cichlid. Ecology Letters, 3(5), 387-393. doi:10.1046/j.14610248.2000.00160.x

Chapman, L. J., \& Hulen, K. G. (2001). Implications of hypoxia for the brain size and gill morphometry of mormyrid fishes. Journal of Zoology (London), 254(4), 461-472.

Chervinski, J. (1983). Salinity tolerance of the mosquito fish, Gambusia affinis ( Baird and Girard ). Journal of Fish Biology, 22(1 983), 9-11.

Clarke, A., \& Johnston, N. M. (1999). Scaling of metabolic rate with body mass and temperature in teleost fish. Journal of Animal Ecology, 68, 893-905.

Da Costa, O. T. F., Pedretti, A. C. E., Schmitz, A., Perry, S. F., \& Fernandes, M. N. (2007). Stereological estimation of surface area and barrier thickness of fish gills in vertical sections. Journal of Microscopy (Oxford), 225(1), 1-9.

Davis, J. C. (1971). Circulatory and ventilatory responses of rainbow trout SalmoGairdneri to artificial manipulation of gill surface area. Journal of the Fisheries Research Board of Canada, 28(10), 1609-1614. 
De Jager, S., Smit-Onel, M. E., Videler, J. J., Van Gils, B. J. M., \& Uffink, E. M. (1977). The respiratory area of the gills of some teleost fishes in relation to their mode of life. Bijdragen tot de Dierkunde, 46(2), 199-205.

Denny, M. W. (1993). Air and Water - The Biology and Physics of Life's Media. Princeton, NJ: Princeton University Press.

Douglas, B.T. (2006). [Ichthyology class project]. unpublished raw data.

Evans, D. H. D., Piermarini, P. M. P., \& Choe, K. P. K. (2005). The multifunctional fish gill: dominant site of gas exchange, osmoregulation, acid-base regulation, and excretion of nitrogenous waste. Physiological Reviews, 85(1), 97-177. doi:10.1152/physrev.00050.2003.

Farrell, A. P., Daxboeck, C., \& Randall, D. J. (1979). Effect of input pressure and flow on the pattern and resistance to flow in the isolated perfused gill of a teleost fish. Journal of Comparative Physiology, 133(3), 233-240.

Farrell, A. P., Sobin, S. S., Randall, D. J., \& Crosby, S. (1980). Intralamellar blood flow patterns in fish gills. American Journal of Physiology - Regulatory Integrative and Comparative Physiology, 8(3).

Fernandes, M. N., \& Perna-Martins, S. A. (2002). Chloride cell responses to long-term exposure to distilled and hard water in the gill of the armored catfish, Hypostomus tietensis (Loricariidae). Acta Zoologica (Copenhagen), 83(4), 321-328.

Gonzales, T. T., Katoh, M., \& Ishimatsu, A. (2008). Respiratory vasculatures of the intertidal air-breathing eel goby, Odontamblyopus lacepedii (Gobiidae : Amblyopinae). Environmental Biology of Fishes, 82(4), 341-351. doi:10.1007/s10641-007-9295-5

Gonzalez, R. J., \& McDonald, D. G. (1992). The relationship between oxygen consumption and ion loss in a freshwater fish. Journal of Experimental Biology, $163,317-332$.

Graham, J. B. (2006). Aquatic and Aerial Respiration. In D. H. Evans \& J. B. Claiborne (Eds.), The Physiology of Fishes (3rd ed., pp. 85-117). Boca Raton, FL: CRC Press.

Gray, I. E. E. (1954). Comparative study of the gill area of marine fishes. Biological Bulletin, 107(2), 219-255.

Helfman, G. S., Collette, B. B., Facey, D. E., \& Bowen, B. W. (2009). The Diversity of Fishes $\left(2^{\text {nd }}\right.$ ed $)$. Chichester, West Sussex, UK: Wiley-Blackwell. 
Hiroi, J., \& McCormick, S. D. (2007). Variation in salinity tolerance, gill $\mathrm{Na}+\mathrm{K}+-$ ATPase, $\mathrm{Na}+/ \mathrm{K}+/ 2 \mathrm{Cl}$ - cotransporter and mitochondria-rich cell distribution in three salmonids Salvelinus namaycush, Salvelinus fontinalis and Salmo salar. Journal of Experimental Biology, 210(6), 1015-1024. doi:10.1242/jeb.002030

Huang, C.-Y. Y., Lee, W., \& Lin, H.-C. C. (2008). Functional differentiation in the anterior gills of the aquatic air-breathing fish, Trichogaster leeri. Journal of Comparative Physiology-Biochemical Systemic and Environmental Physiology, 178(1), 111-121. doi:10.1007/s00360-007-0205-0

Hughes, G. M. (1966). The dimensions of fish gills in relation to their function. The Journal of Experimental Biology, 45(1), 177-95.

Hughes, G. M., \& Morgan, M. (1973). The structure of fish gills in relation to their respiratory function. Biological Review, 48(3), 419-475.

Inokuchi, M., Hiroi, J., Watanabe, S., Hwang, P.-P., \& Kaneko, T. (2009). Morphological and functional classification of ion-absorbing mitochondria-rich cells in the gills of Mozambique tilapia. The Journal of Experimental Biology, 212(Pt 7), 1003-10. doi:10.1242/jeb.025957

Itoh, T. (2006). Tolerance and adaptation of the mosquito-fish Gambusia affinis (Baird \& Girard) to the increase in water salinity in tanks. Japanese Journal of Limnology, 67(3), 219-222.

Lauder, B. Y. G. V. (1984). Pressure and water flow patterns in the respiratory tract of the bass (Micropterus salmoides). Journal of Experimental Biology, 164, 151-164.

LeBlanc, D. M., Wood, C. M., Fudge, D. S., \& Wright, P. A. (2013). A fish out of water: gill and skin remodeling promotes osmo- and ionoregulation in the mangrove killifish Kryptolebias marmoratus. Physiological and Biochemical Zoology, 83(6), 932-49. doi:10.1086/656307

Malte, H., \& Weber, R. E. (1985). A Mathematical Model for Gas Exchange in the Fish Gill Based on Non-linear Blood Gas Equilibrium Curves. Respiration Physiology, 62(August), 359-374.

Matey, V., Iftikar, F. I., Boeck, G. De, Scott, G. R., Sloman, K. A., Almeida-val, V. M. F., Val, A.L., \& Wood, C. M. (2011). Gill morphology and acute hypoxia : responses of mitochondria-rich, pavement, and mucous cells in the Amazonian oscar (Astronotus ocellatus ) and the rainbow trout ( Oncorhynchus mykiss ), two species with very different approaches to the osmo-respirat. Canadian Journal of Zoology, 324, 307-324. doi:10.1139/Z11-002 
Matey, V., Richards, J. G., Wang, Y., Wood, C. M., Rogers, J., Davies, R., Murray, B.W., Chen, X.-Q., Du, J., \& Brauner, C. (2008). The effect of hypoxia on gill morphology and ionoregulatory status in the Lake Qinghai scaleless carp, Gymnocypris przewalskii. Journal of Experimental Biology, 211(Pt 7), 1063-74. doi:10.1242/jeb.010181

McDonald, D. G., Freda, J., Cavdek, V., Gonzalez, R., \& Zia, S. (1991). Interspecific differences in gill morphology of freshwater fish in relation to tolerance of low-pH environments. Physiological Zoology, 64(1), 124-144.

McDonald, D. G., Wood, C. M., Rhem, R. G., Mueller, M. E., Mount, D. R., Bergman, H. L., \& Sanchez, D. A. (1991). Nature and time course of acclimation to aluminum in juvenile brook trout (Salvelinus fontinalis). I. Physiology. Canadian Journal of Fisheries and Aquatic Sciences, 48, 2006-2015.

Mitrovic, D, \& Perry, S. F. (2009). The effects of thermally induced gill remodeling on ionocyte distribution and branchial chloride fluxes in goldfish (Carassius auratus). The Journal of Experimental Biology, 212(Pt 6), 843-52. doi:10.1242/jeb.025999

Mitrovic, Dejana, Dymowska, A., Nilsson, G. E., \& Perry, S. F. (2009). Physiological consequences of gill remodeling in goldfish (Carassius auratus) during exposure to long-term hypoxia. American Journal of Physiology. Regulatory, Integrative and Comparative Physiology, 297(1), R224-34. doi:10.1152/ajpregu.00189.2009

Narahara, A., Bergman, H. L., Laurent, P., Maina, J. N., Walsh, P. J., \& Wood, C. M. (1996). Respiratory physiology of the Lake Magadi tilapia (Oreochromis alcalicus grahami), a fish adapted to a hot, alkaline and frequently hypoxic environment. Physiological Zoology, 69(5), 1114-1136.

Nilsson, G. E. (2007). Gill remodeling in fish - a new fashion or an ancient secret? Journal of Experimental Biology, 210(14), 2403-2409. doi:10.1242/jeb.000281

Olsen, K. R., Farrell, A. P., \& Lutz, P. L. (2006). The cardiovascular system. In D H Evans \& J. B. Claiborne (Eds.), The Physiology of Fishes (Third., pp. 119-152). Boca Raton, FL: CRC Press.

Ong, K. J., Stevens, E. D., \& Wright, P. A. (2007). Gill morphology of the mangrove killifish (Kryptolebias marmoratus) is plastic and changes in response to terrestrial air exposure. The Journal of Experimental Biology, 210(7), 1109-1115. doi:10.1242/jeb.002238

Otto, G. (1973). Temperature tolerance of the mosquitofish, Gambusia afinis (Baird and Girard ). Journal of Fish Biology, 5, 575-585. 
Perry, S. F., Fletcher, C., Bailey, S., Ting, J., Bradshaw, J., Tzaneva, V., \& Gilmour, K. M. (2012). The interactive effects of exercise and gill remodeling in goldfish (Carassius auratus). Journal of Comparative Physiology. B, Biochemical, Systemic, and Environmental Physiology, 182(7), 935-45. doi:10.1007/s00360-012-0673-8

Perry, S. F., Schwaiger, T., Kumai, Y., Tzaneva, V., \& Braun, M. H. (2010). The consequences of reversible gill remodelling on ammonia excretion in goldfish (Carassius auratus). The Journal of Experimental Biology, 213(Pt 21), 3656-65. doi: $10.1242 /$ jeb.045955

Piiper, J., Scheid, P., Perry, S. F., \& Hughes, G. M. (1986). Effective and morphometric oxygen-diffusing capacity of the gills of the elasmobranch Scyliorhinus stellaris. Journal of Experimental Biology, 123, 27-41.

Rasband, W. (2010). Image J. Bethesda, Maryland: National Institutes of Health. Retrieved from http://rsbweb.nih.gov/ij/index.html

Rissanen, E., Tranberg, H. K., Sollid, J., Nilsson, G. E., \& Nikinmaa, M. (2006). Temperature regulates hypoxia-inducible factor-1 (HIF-1) in a poikilothermic vertebrate, crucian carp (Carassius carassius). Journal of Experimental Biology, 209(6), 994-1003. doi:10.1242/jeb.02103

Sandvik, G. K., Nilsson, G. E., \& Jensen, F. B. (2012). Dramatic increase of nitrite levels in hearts of anoxia-exposed crucian carp supporting a role in cardioprotection. American Journal of Physiology. Regulatory, Integrative and Comparative Physiology, 302(4), R468-77. doi:10.1152/ajpregu.00538.2011

Scheid, P, \& Piiper, J. (1971). Theoretical analysis of respiratory gas equilibration in water passing through fish gills. Respiration Physiology, 13(3), 305-318.

Scheid, Peter, Hook, C., \& Piiper, J. (1986). Model for Analysis of Counter-current gas transfer in Fish Gills. Respiration Physiology, 64(March), 365-374.

Scott, G. R., Wood, C. M., Sloman, K. A., Iftikar, F. I., De Boeck, G., Almeida-Val, V. M. F., \& Val, A. L. (2008). Respiratory responses to progressive hypoxia in the Amazonian oscar, Astronotus ocellatus. Respiratory Physiology \& Neurobiology, 162(2), 109-116. doi:10.1016/j.resp.2008.05.001

Sollid, J., De Angelis, P., Gundersen, K., \& Nilsson, G. E. (2003). Hypoxia induces adaptive and reversible gross morphological changes in crucian carp gills. Journal of Experimental Biology, 206(20), 3667-3673. doi:10.1242/jeb.00594

Sollid, J., Kjernsli, A., De Angelis, P. M., Røhr, A. K., Nilsson, G. E., \& Rohr, A. K. (2005). Cell proliferation and gill morphology in anoxic crucian carp. American 
Journal of Physiology Regulatory, Integrative and Comparative Physiology, 289(4), R1196-1201. doi:10.1152/ajpregu.00267.2005

Sollid, J., Rissanen, E., Tranberg, H. K., Thorstensen, T., Vuori, K. a M., Nikinmaa, M., \& Nilsson, G. E. (2006). HIF-1 alpha and iNOS levels in crucian carp gills during hypoxia-induced transformation. Journal of Comparative Physiology B Biochemical Systemic and Environmental Physiology, 176(4), 359-369. doi:10.1007/s00360-005$0059-2$

Sollid, J., Weber, R. E., \& Nilsson, G. E. (2005). Temperature alters the respiratory surface area of crucian carp Carassius carassius and goldfish Carassius auratus. Journal of Experimental Biology, 208(6), 1109-1116. doi:10.1242/jeb.01505

Stensløkken, K. O., Sundin, L., \& Nilsson, G. E. (1999). Cardiovascular and gill microcirculatory effects of endothelin-1 in Atlantic cod: Evidence for pillar cell contraction. Journal of Experimental Biology, 202(9), 1151-1157.

Stevens, E. D., \& Lightfoot, E. N. (1986). Hydrodynamics of water flow in front of and through the gills of skipjack tuna. Comparative Biochemistry and Physiology, $83 A(2), 255-259$.

Turko, A. J., Cooper, C. A., \& Wright, P. A. (2012). Gill remodelling during terrestrial acclimation reduces aquatic respiratory function of the amphibious fish Kryptolebias marmoratus. The Journal of Experimental Biology, 215(Pt 22), 3973-80. doi: $10.1242 /$ jeb.074831

Tzaneva, V., Bailey, S., \& Perry, S. F. (2011). The interactive effects of hypoxemia, hyperoxia, and temperature on the gill morphology of goldfish (Carassius auratus). American Journal of Physiology. Regulatory, Integrative and Comparative Physiology, 300(6), R1344-51. doi:10.1152/ajpregu.00530.2010

Tzaneva, V., Gilmour, K. M., \& Perry, S. F. (2011). Respiratory responses to hypoxia or hypercapnia in goldfish (Carassius auratus) experiencing gill remodelling. Respiratory Physiology \& Neurobiology, 175(1), 112-20. doi:10.1016/j.resp.2010.09.018

Underwood, A. J. (1981). Techniques of Analysis of Variance in Experimental Marine Biology and Ecology. Oceanography and Marine Biology: An Annual Review, 19, 513-605.

Vogel, S. (2003). Comparative Biomechanics - Life's Physical World. Princeton, NJ: Princeton University Press. 
Wilson, J. M., \& Laurent, P. (2002). Fish gill morphology: Inside out. Journal of Experimental Zoology, 293(3), 192-213. doi:10.1002/jez.10124 